\title{
Retrieval of aerosol optical depth in vicinity of broken clouds from reflectance ratios: case study
}

\author{
E. Kassianov ${ }^{1}$, M. Ovchinnikov ${ }^{1}$, L. K. Berg ${ }^{1}$, S. A. McFarlane ${ }^{1}$, C. Flynn ${ }^{1}$, R. Ferrare ${ }^{2}$, C. Hostetler ${ }^{2}$, and \\ M. Alexandrov ${ }^{3}$ \\ ${ }^{1}$ Pacific Northwest National Laboratory, Richland, Washington, 99352, USA \\ ${ }^{2}$ NASA Langley Research Center, Hampton, Virginia, 23681, USA \\ ${ }^{3}$ NASA Goddard Institute for Space Studies, New York, 10025, USA
}

Received: 2 February 2010 - Published in Atmos. Meas. Tech. Discuss.: 21 April 2010

Revised: 14 September 2010 - Accepted: 18 September 2010 - Published: 6 October 2010

\begin{abstract}
A recently developed reflectance ratio (RR) method for the retrieval of aerosol optical depth (AOD) is evaluated using extensive airborne and ground-based data sets collected during the Cloud and Land Surface Interaction Campaign (CLASIC) and the Cumulus Humilis Aerosol Processing Study (CHAPS), which took place in June 2007 over the US Department of Energy (DOE) Atmospheric Radiation Measurement (ARM) Southern Great Plains site. A detailed case study is performed for a field of single-layer shallow cumuli observed on 12 June 2007 . The RR method is applied to retrieve the spectral values of AOD from the reflectance ratios measured by the MODIS Airborne Simulator (MAS) for two pairs of wavelengths $(660$ and $470 \mathrm{~nm}$, 870 and $470 \mathrm{~nm}$ ) collected at a spatial resolution of $0.05 \mathrm{~km}$. The retrieval is compared with an independent AOD estimate from three ground-based Multi-filter Rotating Shadowband Radiometers (MFRSRs). The interpolation algorithm that is used to project MFRSR point measurements onto the aircraft flight tracks is tested using AOD derived from NASA Langley High Spectral Resolution Lidar (HSRL). The RR AOD estimates are in a good agreement (within 5\%) with the MFRSR-derived AOD values for the 660-nm wavelength. The AODs obtained from MAS reflectance ratios overestimate those derived from MFRSR measurements by $15-30 \%$ for the 470-nm wavelength and underestimate the $870-\mathrm{nm}$ AOD by the same amount.
\end{abstract}

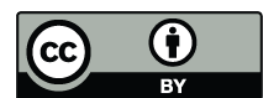

Correspondence to: E. Kassianov (evgueni.kassianov@pnl.gov)

\section{Introduction}

Potential effects of aerosol on clouds and precipitation (termed indirect aerosol effects) and consequently their effects on climate were first suggested several decades ago (Warner, 1968; Twomey, 1977; Albrecht, 1989). However, our understanding of complex aerosol-cloud-precipitation interactions remains far from complete. Atmospheric aerosols can cause a range of effects (Small et al., 2009; Stevens and Feingold, 2009 and references therein) such as (1) increasing albedo due to changes in the cloud droplet concentration and enhancing reflection of solar radiation back into space and (2) altering precipitation and extending lifetime of clouds. Moreover, aerosols can modulate the radiative energy balance of the atmosphere and reduce the amount of solar radiation reaching the surface by absorbing and reflecting sunlight, also called direct radiative forcing. These and other aerosol effects depend strongly on aerosol loading, which is typically characterized by aerosol optical depth (AOD) $\tau_{a}$. Since aerosols can be transported over long distances and aerosol properties vary geographically, their global distribution is particularly essential. Current space borne sensors, such as the MODerate-Resolution Imaging Spectroradiometer (MODIS) and Multiangle Imaging Spectroradiometer (MISR), enable measurements of $\tau_{a}$ and other aerosol properties on both regional and global scales, although typically with coarse resolution and limited accuracy, especially over land (e.g., Mishchenko et al., 2009; Kokhanovsky and de Leeuw, 2009).

Major uncertainties in the satellite-derived $\tau_{a}$ are associated with cloud-induced artifacts in aerosol retrievals, such as subpixel cloud contamination and cloud adjacency effects (e.g., Kobayashi et al., 2000; Mathesonet al., 2005;

Published by Copernicus Publications on behalf of the European Geosciences Union. 
Várnai and Marshak, 2009). The cloud contamination effect comes from partly cloudy pixels which can be misclassified as cloud-free. This effect is more pronounced for coarse resolution satellite observations performed over regions containing small clouds. For example, over the tropical western Atlantic Ocean, the population of misclassified partly-cloudy $1.1-\mathrm{km}$ MISR pixels is found to be $12 \%$ and the corresponding cumulus-induced AOD increase is about $20 \%$ (Zhao et al., 2009). The cloud adjacency effect relates to enhancement (near illuminated cloud sides) and reduction (near shadowy cloud sides) in the reflectance $R$ of cloud-free columns as a result of sunlight scattering by clouds adjacent to the pixel of interest. Since clouds have complex three-dimensional (3D) geometry, a critical assessment of the cloud-induced enhancement/reduction can be obtained by using 3-D radiative transfer calculations for observed or simulated cloud fields (e.g., Cahalan et al., 2001; Nikolaeva et al., 2005; Wen et al., 2006, 2007; Yang and Di Girolamo, 2008). The evidence of a large impact on the retrieved AOD due to the cloud adjacency effect (e.g., Wen et al., 2006, 2007) has led to the development of techniques to address problems associated with cloud-induced enhancement. These problems may be addressed by using three different but overlapping approaches.

The first approach includes selection of clear pixels located far away from clouds/shadows, where the 3-D radiative effects of clouds are relatively small (e.g., Wen et al., 2006, 2007). Statistical analysis of the two-dimensional (2D) horizontal distribution of visible reflectance provides a population of appropriate clear pixels as a function of the nearest cloud distance $(d)$, which determines the range of a completely clear area from a clear pixel of interest and is specified as the distance from the clear pixel to the nearest cloudy pixel (Wen et al., 2006). This population decreases rapidly with $d$ and the rate of decrease is a function of both the cloud fraction (CF) and solar zenith angle (SZA). For example, for a cloud field with $\mathrm{CF} \sim 0.5$ and SZA $\sim 30$ degrees, the clear pixel population is about $5 \%$ and $1 \%$ for $d>2 \mathrm{~km}$ and $d>3 \mathrm{~km}$, respectively (Wen et al., 2007). Therefore, the existing one-dimensional (1-D) operational satellite retrievals of AOD can be successfully applied for a quite limited number of remote (e.g., $d>2 \mathrm{~km}$ ) clear pixels. The measured "remote" aerosol properties may differ substantially from their "near-cloud" counterparts (Su et al., 2008; Tackett and Di Girolamo, 2009; Twohy et al., 2009).

The second approach parameterizes the 3-D radiative effects of clouds on the AOD retrievals. Marshak et al. (2008) proposed such a parameterization based on a simple twolayer model of the atmosphere with broken clouds in the lower layer and only Rayleigh scatterers in the upper layer over dark surface. This parameterization requires several cloud parameters, such as $\mathrm{CF}$, domain-averaged cloud optical depth (COD) and the ratio of cloud thickness to cloud horizontal size. The first two parameters (CF and COD) can be obtained from satellite observations, such as the MODIS Cloud Product (MOD06). Since atmospheric aerosols are not included, the parameterization assumes that only molecular scattering is responsible for the cloud-induced enhancement of reflectance near clouds. A larger increase of reflectance at shorter wavelengths is typically referred to as "bluing" of aerosols near cloud edges (e.g., Wen et al., 2008), while a larger increase of reflectance at longer wavelengths is referred to as "reddening" (Redemann et al., 2009).

The third approach attempts to minimize the $3 \mathrm{D}$ radiative effects of clouds by using multi-spectral observations of reflectance. Kassianov and Ovtchinnikov (2008) proposed to exploit reflectance ratios, which are less sensitive to the 3-D effects of clouds than reflectances themselves. As a result, this method, named the reflectance ratio (RR) method, provides an effective way to reduce substantially the impact of the 3-D effects on the retrieved AOD. To evaluate the potential of the RR method, Kassianov et al. (2009) conducted a sensitivity study and illustrated that it has the ability to detect both "remote" and "nearby" clear pixels appropriate for the RR-based AOD retrievals. Such detection increases the number of appropriate pixels and does not require the statistical analysis of the 2D horizontal distribution of reflectance. Also, the sensitivity study suggested that the RR-based detection of clear pixels and the accuracy of AOD retrievals depend only weakly on the domain-averaged COD.

In this paper, we further evaluate the RR method by using integrated aircraft and ground-based data sets collected during the US Department of Energy (DOE) sponsored Cloud and Land Surface Interaction Campaign (CLASIC) and $\mathrm{Cu}-$ mulus Humilis Aerosol Processing Study (CHAPS). These two campaigns provide intensive measurements of clouds and aerosols on a number of cloudy days. One of these days, 12 June 2007, is selected for this study. This day is characterized by the occurrence of a single-layer of shallow cumuli, aerosol loading that is similar to the climatology and includes multi-spectral observations of the reflected solar radiation obtained at a spatial resolution of $0.05 \mathrm{~km}$ using a high-altitude aircraft. Such high-resolution observations make it possible to substantially reduce the sub-pixel cloud contamination and allow us to focus on the cloud adjacency effect. These observations were accompanied by independent aircraft and surface measurements of AOD. In Sect. 2 we overview CLASIC and CHAPS and describe measurements used in this study. Section 3 outlines the RR method and provides some results from the sensitivity study, which are relevant for our evaluation analysis (Sect. 4). Sections 5 and 6 include discussion and summary, respectively.

\section{CHAPS and CLASIC overview}

The CLASIC and CHAPS took place during June 2007 over the U.S. DOE Atmospheric Radiation Measurement (ARM) Southern Great Plains (SGP) site, which covers parts of Oklahoma and Kansas (Fig. 1). These two complementary field studies were conducted to investigate various aspects 


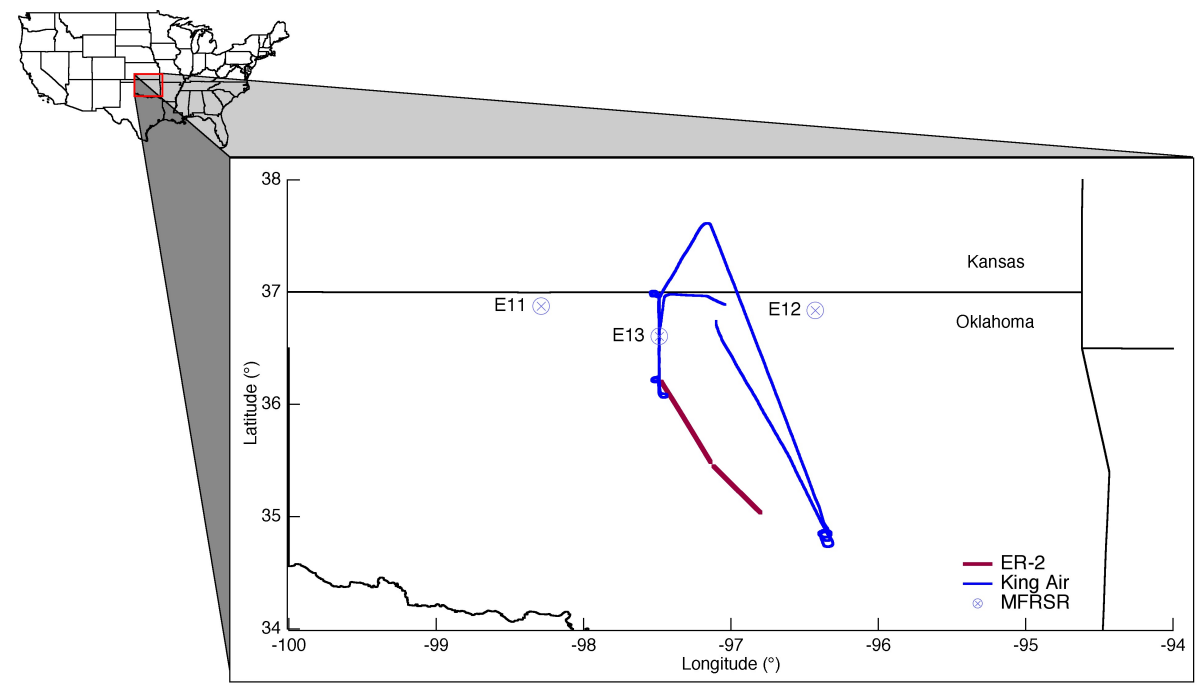

Fig. 1. The general map of aircraft flight tracks with locations of three MFRSRs (circles), and representative flight patterns flown by the ER-2 (red) and the King Air (blue) on 12 June 2007. The corresponding AOD values for these flight patterns are shown in Fig. 9 (Sect. 4 ).

of cloud-aerosol interactions in shallow cumuli and to provide integrated ground-based, aircraft and satellite observations. CLASIC was designed to examine relationships between surface processes and shallow cumuli (Miller et al., 2007). A number of aircraft particpated in CLASIC, including the NASA ER-2 (Fig. 2), which was equipped with the MODIS Airborne Simulator (MAS). The ER-2 flew at 20-km altitude and the MAS measured reflected solar and emitted thermal radiation in 50 channels (from $470 \mathrm{~nm}$ to $14200 \mathrm{~nm}$ ) with high spatial resolution $(0.05 \mathrm{~km})$. There were twelve campaign-related ER-2 flights (http://mas.arc.nasa.gov/data/ deploy html/clasic home.html). We use the RR method to convert the MAS reflectances into the AOD values as described in Sect. 4.

CHAPS was designed to study changes in the optical and chemical properties of particles as they move through shallow cumuli as well as changes to the cloud microphysical properties (Berg et al., 2009). One of the primary instrument platforms used during CHAPS was the NASA Langley King-Air (Fig. 2), which was equipped with the High Spectral Resolution Lidar (HSRL). The HSRL flew at about 9-km altitude and measured profiles of aerosol backscatter and depolarization at two wavelengths $(532 \mathrm{~nm}$ and $1064 \mathrm{~nm}$ ), and profiles of aerosol extinction, and consequently, AOD at one wavelength $(532 \mathrm{~nm})$. There were nineteen campaign-related King Air flights (http://science. larc.nasa.gov/hsrl/chaps/chaps.html).

To evaluate the RR-derived AOD from MAS radiances, we need collocated and coincident estimates of the AOD from independent measurements. Data collected by several instruments (Table 1) during a single cloudy day (12 June 2007) with well-defined single-layer cumuli (Fig. 3) were analyzed. We found that the aircraft data (MAS and HSRL) collected

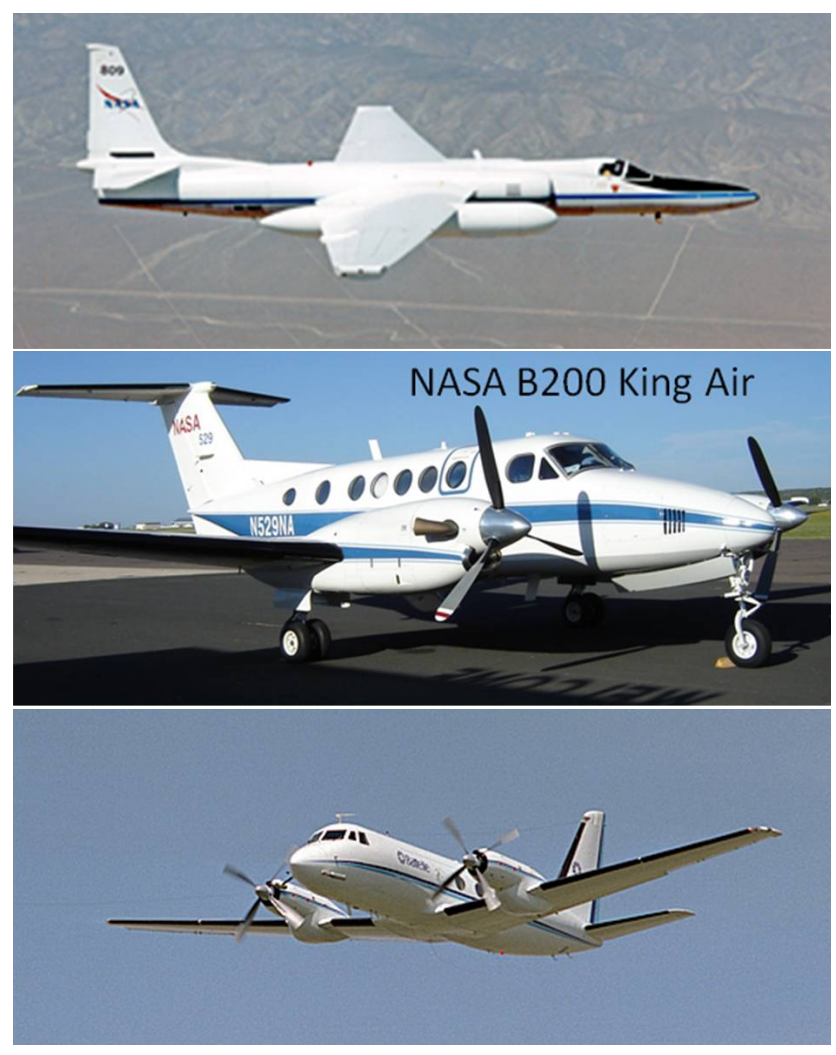

Fig. 2. Photos of the NASA ER-2, NASA Langley B200 King Air, and US DOE G-1. Images are ordered according to the flight altitude used during the CLASIC and CHAPS campaigns, with the ER-2 flying the highest of the three aircraft. 
Table 1. List of key instruments used for obtaining optical and radiative properties of aerosol during the case study period.

\begin{tabular}{|c|c|c|c|c|}
\hline Platform & $\begin{array}{l}\text { Altitude } \\
\text { (a.g.l.) }\end{array}$ & Instrument & $\begin{array}{l}\text { Measured } \\
\text { quantity }\end{array}$ & References \\
\hline $\begin{array}{l}\text { NASA ER-2 } \\
\text { aircraft }\end{array}$ & $20 \mathrm{~km}$ & $\begin{array}{l}\text { Scanning } \\
\text { spectrometer: } \\
\text { MODIS Airborne } \\
\text { Simulator (MAS) }\end{array}$ & $\begin{array}{l}\text { Reflected solar, } \\
\text { emitted thermal } \\
\text { radiation, } \\
50 \text { channels: } \\
(470-14200 \mathrm{~nm})\end{array}$ & $\begin{array}{l}\text { King et al. } \\
(1996) \\
\text { Baum et al. } \\
(2000)\end{array}$ \\
\hline $\begin{array}{l}\text { NASA B200 } \\
\text { King Air } \\
\text { Aircraft }\end{array}$ & $9 \mathrm{~km}$ & $\begin{array}{l}\text { High Spectral } \\
\text { Resolution Lidar } \\
\text { (HSRL) }\end{array}$ & $\begin{array}{l}\text { Profiles of aerosol } \\
\text { backscatter and } \\
\text { depolarization } \\
(532,1064 \mathrm{~nm}) \text {. } \\
\text { Profiles of aerosol } \\
\text { extinction } \\
(532 \mathrm{~nm})\end{array}$ & $\begin{array}{l}\text { Hair et al. } \\
(2008) \\
\text { Rogers et al. } \\
(2009)\end{array}$ \\
\hline \multirow[t]{2}{*}{$\begin{array}{l}\text { DOE } \\
\text { Gulfstream } 1 \\
(\mathrm{G}-1) \text { aircraft }\end{array}$} & $0.8 \mathrm{~km}$ & $\begin{array}{l}\text { Integrating } \\
\text { Nephelometer } \\
\text { (model TSI 3563) }\end{array}$ & $\begin{array}{l}\text { Aerosol scattering } \\
\text { coefficient } \\
(450,550,700 \mathrm{~nm})\end{array}$ & $\begin{array}{l}\text { Berg et al. } \\
(2009)\end{array}$ \\
\hline & & $\begin{array}{l}\text { Radiance Research } \\
\text { Particle Soot } \\
\text { Absorption } \\
\text { Photometer (PSAP) }\end{array}$ & $\begin{array}{l}\text { Aerosol absorption } \\
\text { coefficient } \\
(467,530,660 \mathrm{~nm})\end{array}$ & \\
\hline $\begin{array}{l}\text { ARM surface } \\
\text { network }\end{array}$ & N/A & $\begin{array}{l}\text { Multi-filter Rotating } \\
\text { Shadowband } \\
\text { Radiometer } \\
\text { (MFRSR) }\end{array}$ & $\begin{array}{l}\text { Total and diffuse } \\
\text { solar irradiances } \\
(415,500,615, \\
673,870,940 \mathrm{~nm})\end{array}$ & $\begin{array}{l}\text { Harrison and } \\
\text { Michalsky } \\
\text { (1994) }\end{array}$ \\
\hline
\end{tabular}

for this day (12 June 2007) meet, at least in part, these criteria. The MAS legs 10 and 11 and HSRL observations were made during the same day and over the same general area (Fig. 1). However, the MAS and HRSL flight routes were separated in space and time (Fig. 1). Thus, in a strict sense the MAS and HSRL observations were not collocated or coincident.

To obtain independent AOD estimates along the MAS flight trajectory, we apply AOD values provided by ground-based Multi-filter Rotating Shadowband Radiometers (MFRSRs). These instruments give the spectral values of AOD at six wavelengths $(415,500,615,673,870$ and $940 \mathrm{~nm}$ ). The MFRSR measures spectral values of the total and diffuse solar irradiances with 20-s temporal resolution. These quantities are used to obtain the direct solar irradiances, and consequently, AOD values for clear-sky areas (Harrison and Michalsky, 1994). The MFRSR data for 12 June 2007 were taken from the network operated by the US DOE ARM Program. This network includes 21 sites with the mean distance between neighboring sites of about $80 \mathrm{~km}$. For interpolation of AOD between the MFRSR sites, we used an original technique based on the assumption that AOD fields over the SGP region have the spatial structure of a two-dimensional Fractional Brownian Motion (Appendix A).
This assumption has been verified in the study by Alexandrov et al. (2004a). Unfortunately, on 12 June clear-sky data are available from only 3 MFRSRs (E11, E12, and E13) (Fig. 1). For other sites, clear-sky data are not available because the direct solar beam was frequently blocked by clouds. To cover the area of interest (Fig. 1), the measurements made by the three MFRSR instruments are interpolated. The interpolated MFRSR-derived AOD provide the independent constraint to be compared with those retrived from the MAS observations using the RR method. Uncertainties associated with the MFRSR-based interpolation are estimated by using the HSRL-derived AOD (Sect. 4).

To perform the AOD retrievals from MAS measured reflectances, an estimate of the aerosol single scattering albedo (SSA) is needed as an input to the radiative transfer algorithm to compute look-up tables (LUTs). Note that under clear-sky conditions, the MFRSR-measured diffuse and direct components can be applied succesfuly to estimate SSA (Kassianov et al., 2005, 2007). Under the partly cloudy conditions of 12 June 2007, SSA estimate can be derived from in situ observations (both ground-based and airborne). The Aerosol Observation System (AOS) provides routine ground-based observations of aerosol optical properties at the ARM Central Facility (Sheridan et al., 2001). The AOS draws air through a 


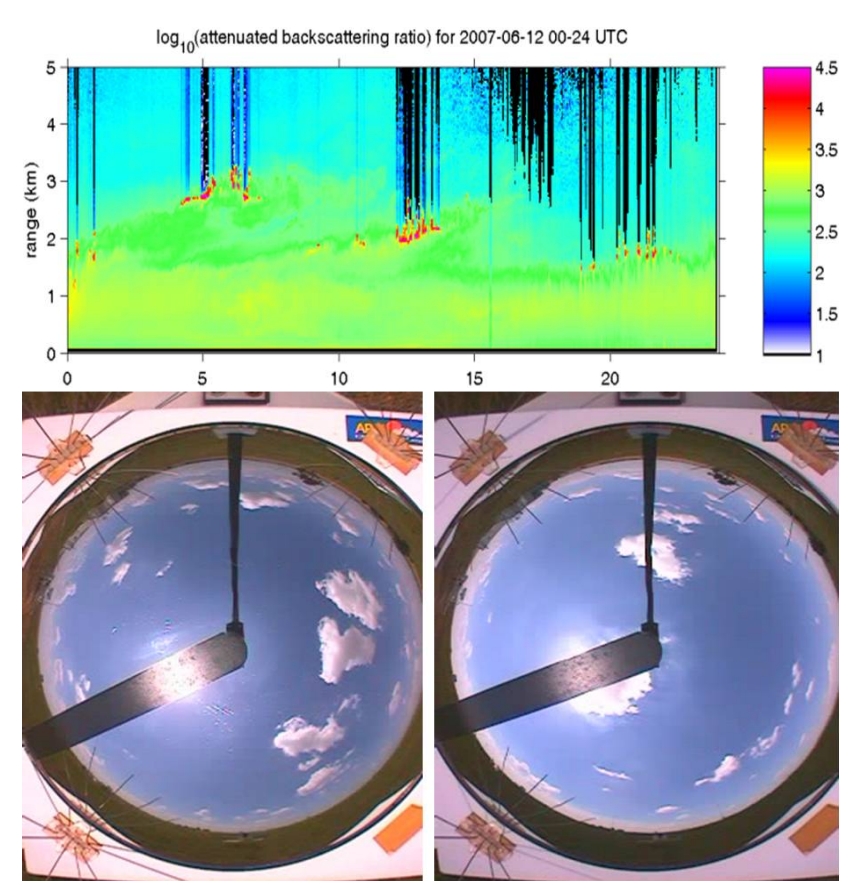

Fig. 3. Two-dimensional images of ground-based micropulse lidar attenuated backscatter $\left(\mathrm{km}^{-1} \mathrm{sr}^{-1}\right)$ (top) and hemispherical total sky images (bottom) for 12 June 2007. Top: The horizontal and vertical axes represent time (UTC) and altitude (km), respectively.

stack $10 \mathrm{~m}$ tall, the air stream is dried to approximately $40 \%$ relative humidity and the scattering and absorption are measured using a TSI 3563 Integrating Nephelometer and Radiance Research Particle Soot Absorption Photometer (PSAP), respectivily. The air stream then passes through a humidifier, and a second measurement of scattering is made. The two aerosol scattering measurements at two different relative humidities (RHs) can be used to determine the aerosol hygroscopic growth factor, $f(\mathrm{RH})$, which is defined as the ratio of the scattering measured at $85 \% \mathrm{RH}$ to the scattering measured at $40 \%$ RH (Sheridan et al., 2001). The SSA is defined as a ratio of observed scattering and extinction for different values of relative humidity (e.g., dry and wet SSA values).

Similar to the AOS, the US DOE Gulfstream 1 (G-1) aircraft provides observations of aerosol optical properties at different altitudes. Berg et al. (2009) present the full instrument payload on board the G-1, which includes two TSI 3563 Integrating Nephelometers for measuring aerosol scattering and two PSAPs to measure particle absorption. A total of eight research flights with the G-1 were conducted during the CHAPS campaingn. The G-1 measurements made on 11, 13 and 14 June are of particular interest to this study. The average growth factor over the three-day period observed at the surface was 2.54 , which was much larger than the longterm average of 1.83 presented by Sheridan et al. (2001). The SSA was calculated using both the dry ( $40 \%$ relative humidity) and wet ( $85 \%$ relative humidity) values of scattering. On

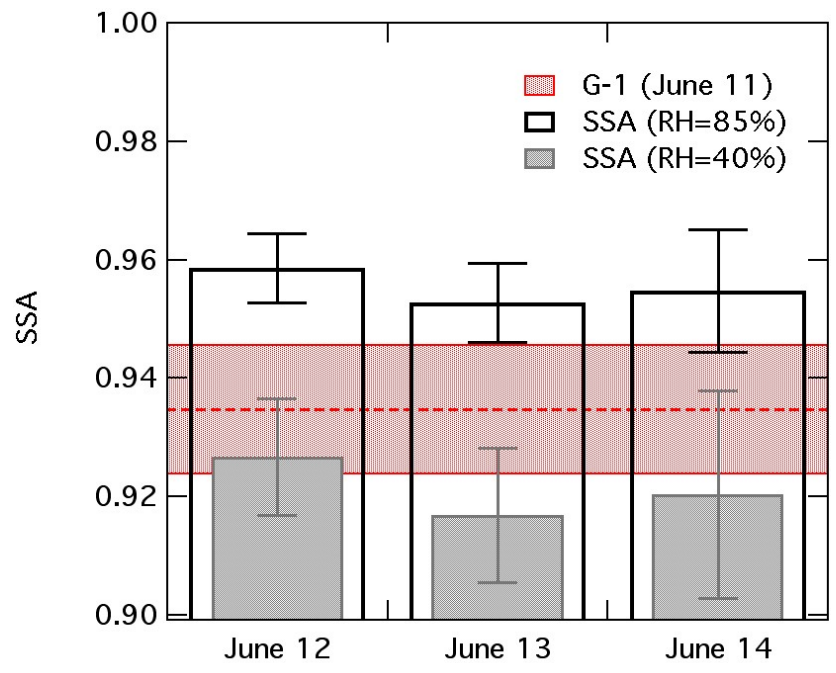

Fig. 4. Daily average mean surface SSA on 12 June through 14 June 2007 at the ACRF Central Facility for RH of 40\% (grey), SSA for the same days for RH of $85 \%$ (black), and average SSA computed form G-1 flight leg on 11 June (dashed red line). Error bars for surface measurements indicate the standard deviation for that day, and red shading indicates the standard deviation of SSA measured by the G-1.

12 June, the 24-h average dry SSA associated with particles less than $10 \mu \mathrm{m}$ in diameter was 0.927 , while the wet SSA was nearly 0.96 (Fig. 4). Absorption data from the ACRF Central Facility was not available on 11 June; therefore only surface measurements made on 13 and 14 June were included in Fig. 4. The SSA over these three days is nearly constant with differences within the daily-range variability, suggesting that aerosol absorbing properties did not vary systematically over that period. Measurements of SSA at a relative humidity of $35 \%$ were made on board the G-1 aircraft in relatively clean air just south of Oklahoma City, Oklahoma. The average SSA value (0.934) from a flight on 11 June is shown in Fig. 4. This leg was flown approximately $800 \mathrm{~m}$ above ground and $300 \mathrm{~m}$ below cloud base. These results are broadly consistent with a finding from a two-year study at the ARM Central Facility that SSA values measured at the surface were slightly smaller than those measured aloft (Andrews et al., 2004). We use an SSA of 0.95 for generating of LUTs, and thereafter for the AOD estimations from the MAS-measured reflectances by using the RR method (Sect. 4).

\section{RR method and sensitivity study results}

In traditional retrievals, AOD is obtained from the observed reflectance using pre-calculated LUTs generated by a one-dimensional (1-D) radiative transfer model for a range of observational conditions and viewing geometries (e.g., Kokhanovsky and de Leeuw, 2009). Assumed aerosol optical 
properties (e.g., AOD, SSA, phase function) and surface albedo enter into the radiative transfer calculations as input. An underlying assumption of this approach is that 1-D reflectance closely approximates the real (3-D) reflectances. This assumption is violated for partially cloudy scenes with significant horizontal inhomogeneity. Similar to traditional aerosol retrievals, the RR method (Kassianov and Ovtchinnikov, 2008) is also based on LUTs generated by a 1-D radiative transfer model but assumes that the 1-D reflectance ratio $\rho_{1 \mathrm{D}}\left(\lambda_{2} ; \lambda_{1}\right)$ approximates the 3 -D reflectance ratio $\rho_{3 \mathrm{D}}\left(\lambda_{2} ; \lambda_{1}\right)$, where $\rho\left(\lambda_{2} ; \lambda_{1}\right)$ is the ratio of reflectances $R\left(\lambda_{2}\right)$ and $R\left(\lambda_{1}\right)$ at two wavelengths $\lambda_{2}$ and $\lambda_{1}$. This assumption is motivated by the well-known fact that clouds reflect about the same amount of sunlight regardless of the wavelength and consequently the reflectance ratio is less sensitive to 3-D radiative effects of clouds than reflectance (Kassianov and Ovtchinnikov, 2008). The second assumption of the RR method is that the spectral behavior of $\tau_{a}$ is described by a two-parameter power law $\tau_{a}(\lambda)=\beta \lambda^{-\alpha}$ (e.g., von Hoyningen-Huene, 2003; Katsev et al., 2010). The two parameters $\alpha$ and $\beta$ are known as the Angstrom exponent and the turbidity coefficient, respectively. This assumption is motivated by widespread practical use of different twoparameter fits of $\tau_{a}(\lambda)$ in aerosol-related studies and satellite retrievals, such as in the MODIS and Advanced Very High Resolution Radiometer (AVHRR) operational aerosol retrieval algorithms.

In contrast to traditional aerosol retrievals, the RR-based LUTs link two reflectance ratios (two knowns) and two parameters $\alpha$ and $\beta$ (two unknowns). For given observational conditions and viewing geometry, the link can be written as

$\rho_{\alpha \beta}\left(\lambda_{2} ; \lambda_{1}\right)=f_{1}(\alpha, \beta)$

$\rho_{\alpha \beta}\left(\lambda_{3} ; \lambda_{1}\right)=f_{2}(\alpha, \beta)$

The RR method includes two basic steps described in detail by Kassianov and Ovtchinnikov (2008) and briefly summarized here. The first step defines parameters $\alpha$ and $\beta$ by replacement of the 1-D reflectance ratios $\rho_{\alpha \beta}\left(\lambda_{2} ; \lambda_{1}\right)$ and $\rho_{\alpha \beta}\left(\lambda_{3} ; \lambda_{1}\right)$ by their "observed" 3-D counterparts $\rho_{\text {obs }}\left(\lambda_{2} ; \lambda_{1}\right)$ and $\rho_{\text {obs }}\left(\lambda_{3} ; \lambda_{1}\right)$ in Eq. (1). Such replacement represents the first assumption specified in the previous paragraph. The second step uses the second assumption and estimates $\tau_{a}(\lambda)$ by using the defined parameters $(\alpha, \beta)$ and assumed power law. The selection of appropriate wavelengths $\left(\lambda_{1}, \lambda_{2}, \lambda_{3}\right)$ in Eq. (1) is governed by the existence and uniqueness of their solution. Graphically, the solution of Eq. (1) is an intersection point of two isolines of constant reflectance ratios in the $(\alpha, \beta)$ domain. When these isolines are nearly orthogonal over much of the $(\alpha, \beta)$ domain, a unique solution for the $(\alpha, \beta)$ pair can be obtained (Appendix B). Note that we considered three wavelengths $(470,660$ and $870 \mathrm{~nm}$ ). Some of these wavelengths may not be available for other aircraft- and space-born instruments, which measure reflected solar radiation. For example, the 470-nm channel is not included in widely-used radiometers, such as AVHRR and Multiangle Imaging Spectroradiometer (MISR). Therefore, the adaption of the RR method to these radiometers would require additional studies for selecting other combinations of wavelengths.

A key question in the obtaining of parameters $(\alpha, \beta)$ relates to how random errors in the reflectance ratios can change the solution of Eq. (1), and consequently, the retrieved AOD. If the solution changes significantly, the retrieval would not be considered to be stable. These errors can be attributed by uncertainties in sensor characteristics (e.g., calibration), the atmospheric conditions (e.g., aerosol SSA) and surface properties (e.g., surface albedo). The radiometric calibration of the MAS shortwave channels $(<2500 \mathrm{~nm})$ is discussed by King et al. (2010). In particular, the calibration adjustment is about $7 \%$ at $660 \mathrm{~nm}$ (King et al., 2010). It is customary to express the reflectance as the sum of regular $\bar{R}(\lambda)$ and fluctuating $\tilde{R}(\lambda)$ components

$R(\lambda)=\bar{R}(\lambda)+\tilde{R}(\lambda)$

A sensitivity study by Kassianov et al. (2009) assessed the performance of the RR method when random errors $\tilde{R}(\lambda)$ were specified as $\tilde{R}(\lambda)=\gamma(\lambda) \bar{R}(\lambda)$ and noise $\gamma(\lambda)$ was distributed uniformly over the interval $(-0.05 ; 0.05)$. In particular, the sensitivity study included two limiting cases with spectrally dependent and spectrally independent errors. The study showed that the spectrally correlated errors do not significantly affect the number of pixels where the RR-based retrieval of AOD is possible or the RR-derived AOD values. On the other hand, spectrally independent fluctuations of $R(\lambda)$ can increase substantially the number of pixels where large (>50\%) positive and negative AOD biases occur. The domain-averaged values of the retrieved AOD, however, depend only weakly on $\tilde{R}(\lambda)$ because negative and positive biases tend to cancel each other. In contrast, the total number of clear pixels with retrieved AOD $\left(N_{\mathrm{AOD}}\right)$ is sensitive to the random errors $\tilde{R}(\lambda)$. For example, $N_{\mathrm{AOD}}$ is reduced by about $20 \%$ when small $(\leq 5 \%)$ but spectrally independent random errors were introduced in the reflectances. Such reduction can be explained as follows. Spectrally independent errors in reflectances can be amplified substantially for some clear pixels leading to large uncertainties in reflectance ratios. As a result, the reflectance ratios can move outside the valid ranges specified in the generated LUTs, in which case the RR method does not provide the AOD retrieval for such pixels.

The sensitivity study (Kassianov et al., 2009) assessed the performance of the RR method for a realistic variety and range of input parameters encountered at the ACRF SGP site. The results of the sensitivity study suggested that the RR method has the ability to estimate quite accurately the domain-averaged AODs under broken cloud conditions. We further evaluate the RR method by using data collected during the CHAPS and CLASIC campaigns that are discussed in Sect. 2. 


\section{Evaluation of the RR method}

The evaluation of the RR method includes (1) estimation of the RR-derived AOD values and (2) their comparison with independent AOD estimates. The RR-derived AOD values (Sect. 4.1) are obtained by the RR method. We determine parameters $\alpha$ and $\beta$ by applying the RR method to the cloudysky MAS-measured reflectances. Then these parameters $(\alpha$ and $\beta$ ) are used to specify the spectral values of AOD. Independent AOD estimates are obtained by spatial and temporal interpolation of the MFRSR-derived AODs (Sect. 4.2). First, we assess uncertainties associated with the AOD interpolation by comparing the MFRSR- and HSRL-derived AODs along the HSRL flight track. Then the AOD interpolation is used to obtain the MFRSR AODs along the MAS flight trajectory. These MFRSR-obtained AODs are then compared to those provided by the RR method.

\subsection{RR-derived AOD}

To convert the MAS reflectances (Fig. 5) into the AOD values, we generate the LUTs for given observational conditions. During 12 June 2007, two legs 10 and 11 of the MAS flights had the closest temporal and spatial overlap with the NASA King Air flight pattern. The corresponding mean values of the SZA are 40 and 41 degrees for legs 10 and 11, respectively. We generate the LUTs for these two SZAs and assumed values of aerosol SSA and surface albedo $A_{\mathrm{S}}$. Results of our analysis (Sect. 2) demonstrate that on this day the aerosol was slightly absorbing (SSA $\sim 0.95)$ and that groundand aircraft-based SSA values are comparable. Thus, we assume that the aerosol SSA is equal to 0.95 for all three wavelengths (470, 660 and $870 \mathrm{~nm})$ and does not change significantly with altitude in the boundary layer. However, the vertical distributions of other aerosol properties (e.g., extinction coefficient) are not vertically uniform and represent typical profiles observed during the CLASIC and CHAPS campaigns. Also, these campaigns include satellite- and groundbased measurements of surface albedo $A_{\mathrm{S}}$, which is a complex function of land cover type, aerosol loading, cloud properties and SZA (e.g., Yang et al., 2008). Note that the area surrounding the ARM Central Facility contains 10 main land cover types (e.g., Luo et al., 2005) and it is characterized by substantial spatial variability of $A_{\mathrm{S}}$. The sensitivity of the RR-retrieved AOD to $A_{\mathrm{S}}$ is considered next.

We start with analysis of available information of $A_{S}(\lambda)$ at the ARM Central Facility and surrounding area obtained from surface and satellite observations (e.g., Michalsky et al., 2003; Yang et al., 2008). The main objective of such analysis is to define typical spectral variations of $A_{S}(\lambda)$. For example, the 6-channel upward-looking MFRSRs and downwardlooking Multi-filter Radiometers (MFRs) on $10 \mathrm{~m}$ and $25 \mathrm{~m}$ towers at the ARM Central Facility are applied to estimate spectral values of $A_{S}(\lambda)$ at six MFRSR wavelengths. Values of surface albedo at other wavelengths are obtained by
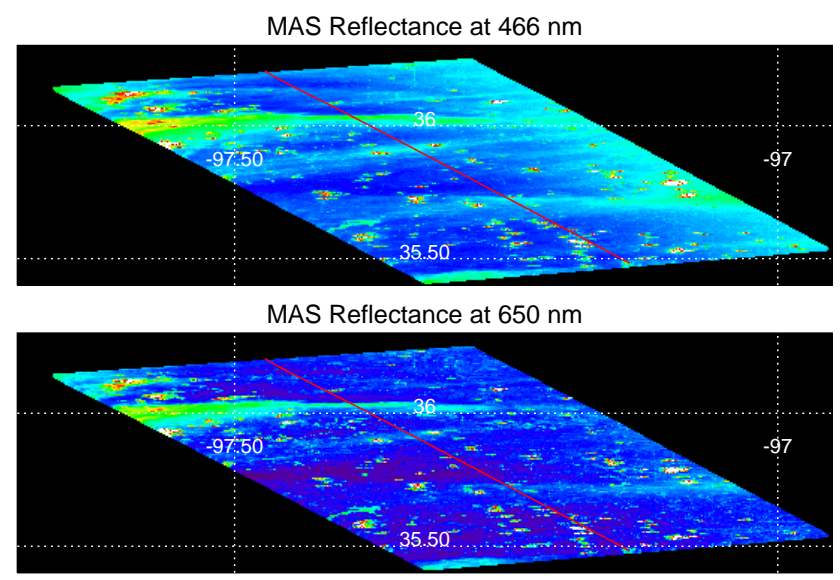

MAS Reflectance at $866 \mathrm{~nm}$

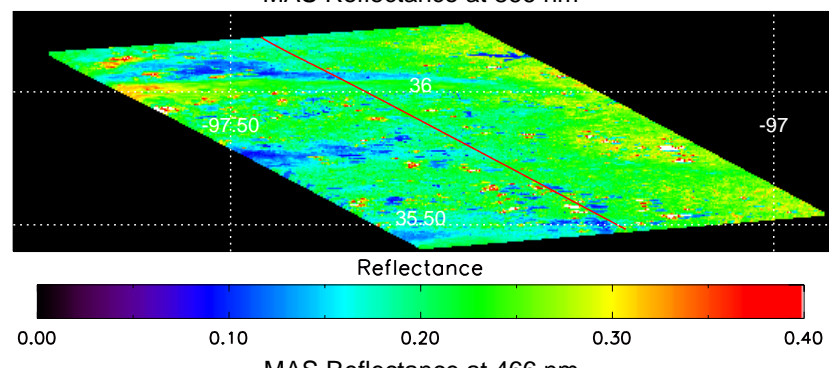

MAS Reflectance at $466 \mathrm{~nm}$

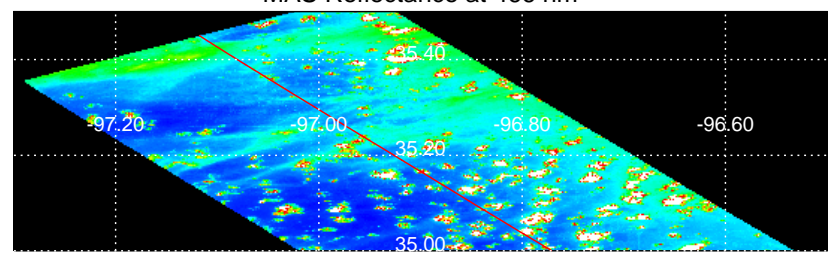

MAS Reflectance at $650 \mathrm{~nm}$
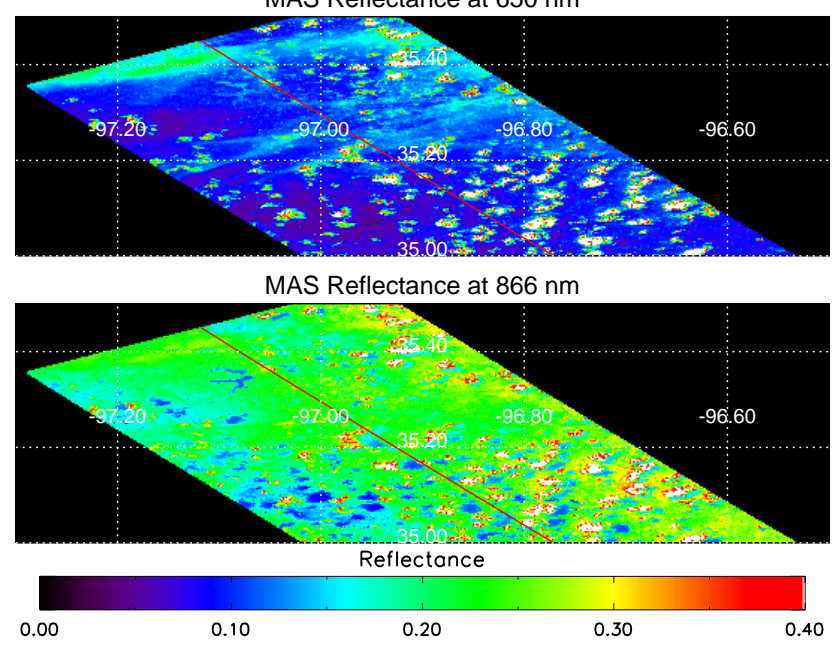

Fig. 5. Cloudy-sky reflectance measured by MAS for leg 10 (top panel) and leg 11 (bottom panel) as function of wavelength: $466 \mathrm{~nm}$ (top), $650 \mathrm{~nm}$ (middle) and $866 \mathrm{~nm}$ (bottom). Solid lines in the middle of these images define tracks of the ER-2 flights during 12 June 2007. 
Table 2. Initial values, increments and the corresponding ranges of assumed surface albedo as functions of wavelengths.

\begin{tabular}{cclc}
\hline $\begin{array}{c}\text { Wavelength } \\
(\mathrm{nm})\end{array}$ & $\begin{array}{c}\text { Initial value, } \\
A_{\lambda}\end{array}$ & $\begin{array}{l}\text { Increment, } \\
\Delta A_{\lambda}\end{array}$ & $\begin{array}{c}\text { Range } \\
\text { (min-max) }\end{array}$ \\
\hline 470 & 0.03 & 0.005 & $0.03-0.06$ \\
660 & 0.07 & 0.01 & $0.07-0.13$ \\
870 & 0.20 & 0.02 & $0.20-0.32$ \\
\hline
\end{tabular}

interpolation. At the ARM SGP site, the typical spectral values $A_{S}(\lambda)$ vary over a broad range: $(0.03-0.06),(0.07-0.13)$ and $(0.20-0.32)$ for the wavelengths 470,600 and $870 \mathrm{~nm}$, respectively. To represent such spectral variations, we develop the LUTs, which cover these ranges. Specifically, we calculate the LUTs for the following values of $A_{\mathrm{S}}(\lambda)$

$A_{\mathrm{S}, \lambda}(i)=A_{\lambda}+\Delta A_{\lambda} \times(i-1)$,

$i=1, \ldots, N_{\mathrm{A}}$

where $A_{\lambda}$ and $\Delta A_{\lambda}$ are their initial values and increments (Table 2). We assume that the number of bins $N_{\mathrm{A}}$ is equal to 7 . Thus, for the three wavelengths, the total number of created LUTs is $343\left(7^{3}=343\right)$. For each LUT, we obtain a population of clear pixels where the AOD is retrieved using the RR-method. The population size, $N_{\mathrm{AOD}}$, depends substantially on the assumed surface albedo: it decreases by about 10 times with increase of $A_{S}(\lambda)$ from 0.20 to 0.32 (Fig. 6). In comparison with $N_{\mathrm{AOD}}$, the domain-averaged retrieved AOD values at $660 \mathrm{~nm}$ are not sensitive to the assumed $A_{\mathrm{S}}(\lambda)$ (Fig. 6). The observed weak AOD dependence at $660 \mathrm{~nm}$ is consistent with the sensitivity study results (Sect. 3). The assumed $A_{\mathrm{S}}(\lambda)$ has a noticeable impact on the Angstrom exponent of the retrieved AOD (Appendix C): it increases from 1.20 to 1.54 when $A_{\mathrm{S}}(\lambda)$ increases from 0.20 to 0.32 . Note that an accurate estimation of the Angstrom exponent from satellite-obtained AODs represents a great challenge even for clear-sky conditions (e.g., Mischenko et al., 2010). As a result, the satellite-based AOD retrievals and their comparisons are performed typically for a given wavelength.

Below, we show the RR-derived AOD values (legs 10 and 11), which represent the largest populations $N_{A O D}^{*}$. The number of pixels $N_{\text {AOD }}^{*}$ equals 701 and 533 for leg 10 and leg 11, respectively. The corresponding spectral values of the surface albedo are $A_{\mathrm{s}, 470}^{*}=0.06, A_{\mathrm{s}, 660}^{*}=0.07$ and $A_{\mathrm{s}, 870}^{*}=0.22$ and these values are the same for legs 10 and 11. Since the mean values of the RR-retrieved AOD are largely unaffected by uncertainties in the reflectance (Sect. 3), we compare the mean values with those provided by MFRSR observations.

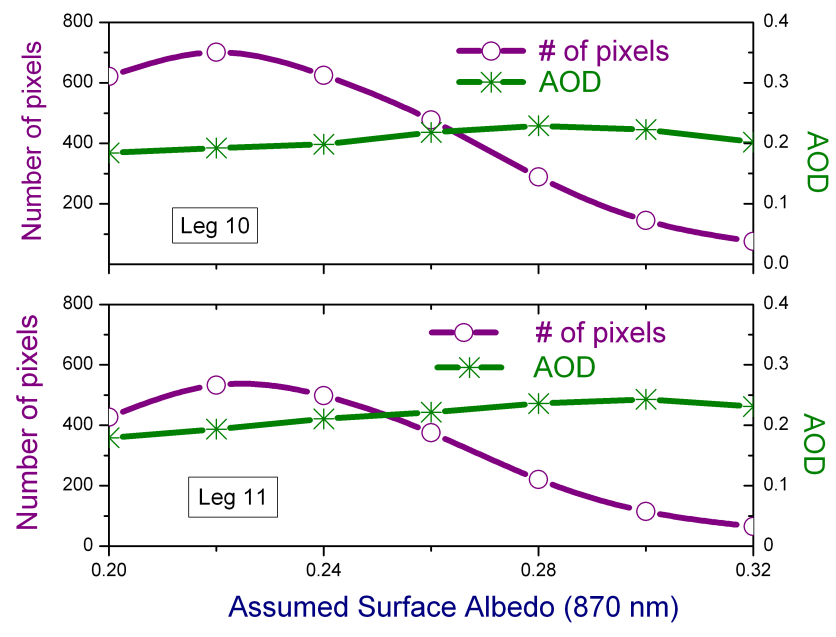

Fig. 6. Example of the RR-based AOD retrieval: population of clear pixels with the retrieved AOD and the domain-averaged AOD $(660 \mathrm{~nm})$ as function of assumed surface albedo $(870 \mathrm{~nm})$ for leg 10 (top) and leg 11 (bottom).

\subsection{MFRS-derived AOD}

The spectral AOD values at six wavelengths are supplied by three MFRSRs located at three sites (Sect. 2). The temporal and spatial interpolation of the MFRSR data (Sect. 2), allows us to obtain the MFRSR-derived AOD for time instances and locations of interest. In other words, such interpolation makes it possible to get the "collocated" and "coincident" MFRSR and MAS observations.

To estimate uncertainties associated with the AOD interpolation, we obtain the spatially and temporally interpolated MFRSR-derived AOD values $(500 \mathrm{~nm})$ along the HSRL flight trajectory and then compare these values with those derived by the HSRL ( $532 \mathrm{~nm}$ ). The latter are obtained using an established approach (Hair et al., 2008; Rogers et al., 2009). The HSRL observations include about 3-h of data (collected from 18:30 to 21:30 UTC) and show substantial temporal and spatial variability of aerosol properties along the HSRL path (Fig. 7). Different meteorological conditions or air-mass histories may be responsible for the observed variations. In general, the MFRSR-provided AODs reproduce the HSRLobserved AOD variations quite well (Fig. 8). For example, the transition from an air mass with an optically thick population of aerosol to an air mass with optically thin population (around 20:25 UTC) is captured by both the MFRSR and HSRL data, with only a small $(\sim 10 \mathrm{~min})$ temporal delay in the MFRSR-derived AOD. The corresponding 3-h averaged values of the HSRL- and MFRSR-derived AODs are 0.18 and 0.22 , respectively (Fig. 8). This comparison suggests that, on average, the AOD interpolation works reasonably well and the associated uncertainties in the mean AODs obtained by these two methods are about 0.04 (or 20\%). The MFRSRand HSRL-derived AODs represent the whole atmospheric 


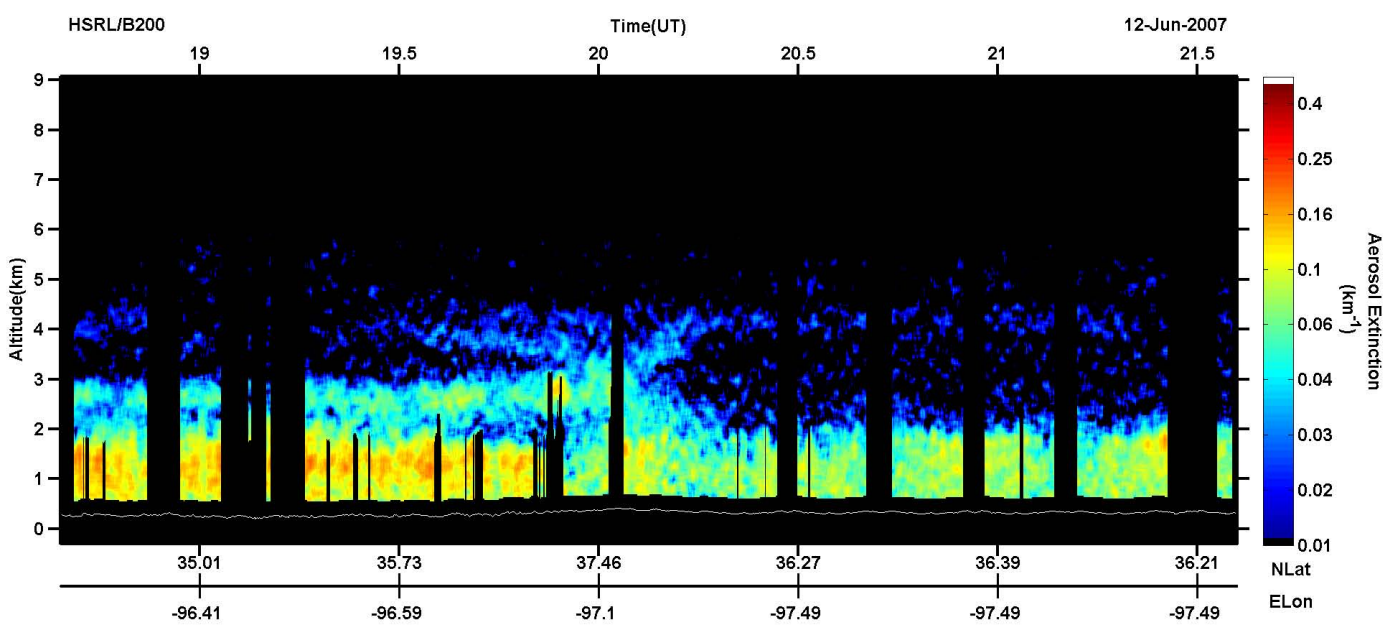

Fig. 7. Two-dimensional images of aerosol extinction coefficient at $532 \mathrm{~nm}$ obtained from HSRL data as function of latitude and longitude (the bottom of figure). The HSRL flight had a complex spatial pattern (Fig. 1), thus the corresponding monotonic temporal scale is also given at the top of figure.

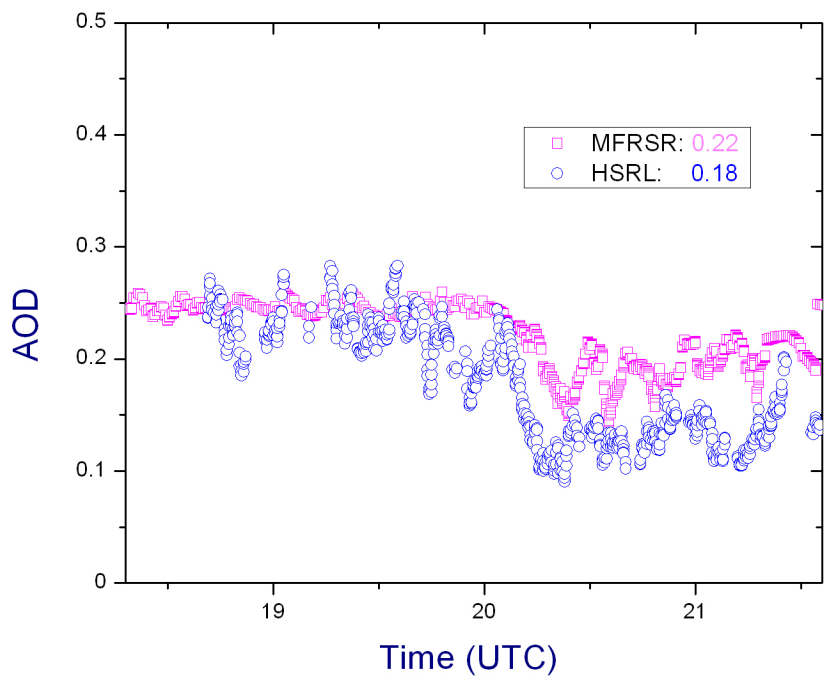

Fig. 8. Temporal realizations of the MFRSR- and HSRL-derived AOD along the HSRL track. Corresponding mean values $(0.22$ and 0.18 ) are shown.

column (from surface to the top of the atmosphere) and a 9$\mathrm{km}$ thick layer, respectively. Thus, aerosols located above the HSRL flight altitude $(9 \mathrm{~km})$ can contribute slightly $(\sim 0.01)$ to the observed differences between the HSRL- and MFRSRderived AODs.

We use the MFRSR-derived AODs interpolated to the MAS track for comparison with the corresponding RRderived AODs. Figures 9 and 10 show that the spectral values of the RR- and MFRSR-derived AODs correlate quite well, with better agreement between the RRand MFRSR-derived AODs for leg 11 (Fig. 10). For both legs, the RR- and MFRSR-derived AOD are close (within
$5 \%$ ) for the 660-nm wavelength. In comparison with the MFRSR data, the RR method overestimates (underestimates) AOD values for wavelengths shorter (longer) than $660 \mathrm{~nm}$ (Fig. 10). The corresponding absolute (relative) differences are about $0.04-0.07(16-29 \%)$ and $0.02-0.03(15-20 \%)$ for wavelengths $470 \mathrm{~nm}$ and $870 \mathrm{~nm}$, respectively. Under clearsky conditions, uncertainties of the MFRSR-derived AOD are about 0.01-0.02 (Michalsky et al., 2006) and the expected uncertainties of the MODIS-derived AOD typically fall within $\pm 0.05 \pm 0.15 \tau_{a}$ over land (Remer et al., 2005). Under cloudy-sky conditions, the cloud-induced enhancement may be responsible for much larger overestimation of the MODIS-derived AOD (e.g., Wen et al., 2006, 2007).

\section{Discussion}

The observed differences between the spectral dependence of RR- and MFRSR-derived AODs (Sect. 4) can be attributed to several factors. The first factor is related to the sampling issues. The MAS sampling of reflectances is performed along the flight track, whereas the MFRSR sampling of direct normal irradiances (direct beam) is made at three ground-based sites followed by appropriate interpolation of the MFRSRderived AODs (Sect. 2). As determined by comparing the MFRSR-and HSRL-derived AODs, the uncertainties associated with the AOD interpolation are about $0.04(20 \%)$ for the $500-\mathrm{nm}$ wavelength. These uncertainties may have spectral dependence. The second factor is related to the cloud screening. The RR-based cloud screening is based on the spectral variations of reflectance ratios (Kassianov et al., 2009), whereas the MFRSR-based cloud screening incorporates the temporal variability of retrieved optical depth (Alexandrov, 2004b). These different cloud screenings can provide different number of retrieved AODs in vicinity of clouds. Such 


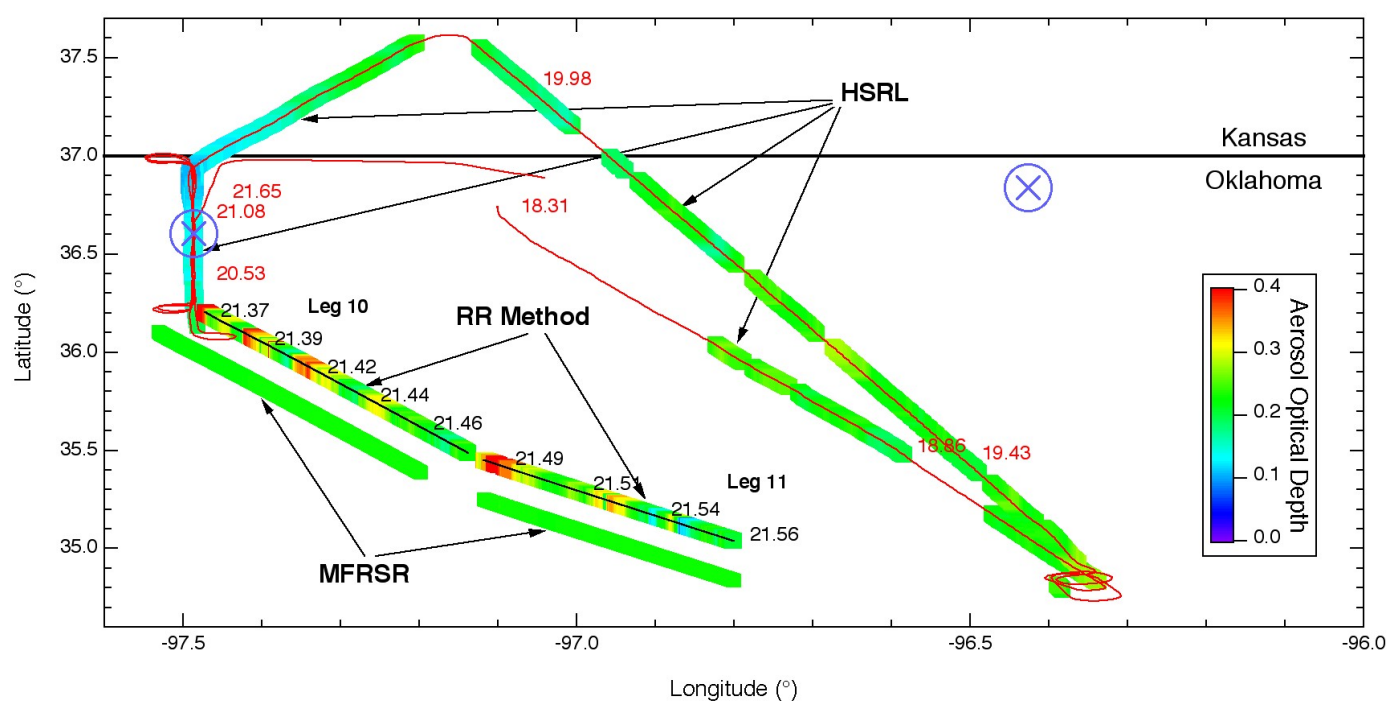

Fig. 9. Map of AOD obtained from the RR, HSRL and MFRSR retrievals (colored lines). Warmer colors indicate larger AOD. The RR retrieval is performed for the MAS-measured reflectances along the MAS flight legs 10 and 11. The more western RR retrieval corresponds to the flight leg 10. Numbers along the colored lines denote the corresponding time of day (UTC) and circles define locations of two MFRSRs. The MFRSR-derived AOD is interpolated spatially and temporally to represent the AOD along the MAS flight trajectory (legs 10 and 11). To ease the comparison of the RR- and MFRSR-derived AODs, the latter are slightly shifted down and to the left (toward the southwest).
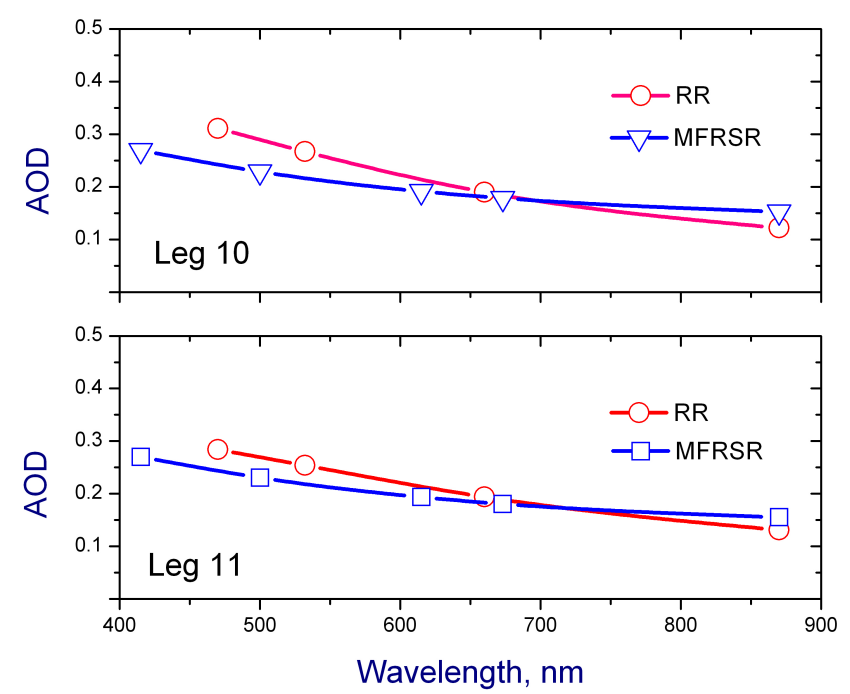

Fig. 10. Spectral dependence of the domain-averaged AOD values obtained from the RR and MFRSR retrievals for leg 10 (top) and leg 11 (bottom).

"nearby" AOD values depend on relative humidity $(\mathrm{RH})$ in a cloud layer in a complex and ambiguous way. For example, large changes of Angstrom exponent, which defines the spectral dependence of AOD, can be produced for the bimodal aerosol size distribution and these changes are governed by the accumulation mode fraction and RH (Loeb and Schuster, 2008). Note that the uncertainties in surface albedo can modify substantially the population of clear pixels with the retrieved AOD $N_{\mathrm{AOD}}$ (Sects. 3 and 4 ) and thus change the corresponding "near-cloud" AOD values.

The largest population of pixels determined using the RR method $N_{\text {AOD }}^{*}$ is obtained for the following spectral values of the surface albedo: $A_{\mathrm{s}, 470}^{*}=0.06, A_{\mathrm{s}, 660}^{*}=0.07$ and $A_{\mathrm{s}, 870}^{*}=0.22$ (Sect. 4). These values can be considered as an "effective" domain-averaged (along flight track) values for given observational (e.g., aerosol and cloud properties) and illumination (SZA) conditions. Since the spatial resolution of the MAS observations is $0.05 \mathrm{~km}$ and population $N_{\mathrm{AOD}}^{*}$ equals 701 for leg 10 and 533 for leg 11, these "effective" values represent samples with a horizontal swath of about $35 \mathrm{~km}$ along leg 10 and $25 \mathrm{~km}$ along leg 11 . The estimation of these "effective" values required a substantial (343) number of LUTs (Sect. 4). For the given area of interest and set of wavelengths, the number of LUTs is defined by the $A_{\mathrm{S}}(\lambda)$ range and the specified number of bins $N_{\mathrm{A}}$ (Sect. 4). Since the detailed information about $A_{S}(\lambda)$ is not required for the RR-based AOD retrieval (Sect. 4), larger increments $\Delta A_{\lambda}$ can be used to reduce the number of bins $N_{\mathrm{A}}$. If necessary, intermediate values of $A_{\mathrm{S}}(\lambda)$ can be determined using appropriate interpolation between bins. Such an approach based on $N_{\mathrm{A}}$ reduction and interpolation can decrease substantially (by a factor of ten) the total number of created LUTs. Also, information about the surface albedo can be obtained from independent satellite/ground-based observations or climatological records (e.g., Kokhanovsky and de Leeuw, 2009). In that event, the RR method includes a single LUT, which represents the independent data. To examine 
Table 3. Acronyms.

\begin{tabular}{ll}
\hline AOD & Aerosol optical depth \\
AOS & Aerosol Observation System \\
ARM & Atmospheric Radiation Measurement \\
ASP & Atmospheric Science Program \\
CF & Cloud fraction \\
CHAPS & Cumulus Humilis Aerosol Processing Study \\
CLASIC & Cloud and Land Surface Interaction Campaign \\
COD & Cloud optical depth \\
$d$ & Nearest cloud distance \\
DOE & Department of Energy \\
EMSL & Environmental Molecular Sciences Laboratory \\
G-1 & Gulfstream-1 aircraft \\
HSRL & NASA Langley High Spectral Resolution Lidar \\
LUT & Look-up table \\
MAS & MODIS Airborne Simulator \\
MFR & Multi-filter Radiometer \\
MFRSR & Multi-filter Rotating Shadowband Radiometer \\
MISR & Multiangle Imaging Spectroradiometer \\
MODIS & MODerate-Resolution Imaging Spectroradiometer \\
MSCF & Molecular Science Computing Facility \\
NASA & National Aeronautics and Space Administration \\
OBER & Office of Biological and Environmental Research \\
PSAP & Radiance Research Particle Soot Absorption Photometer \\
PNNL & Pacific Nortnwest National Laboratory \\
RH & Relative humidity \\
RR & Reflectance ratio \\
SGP & Southern Great Plains \\
SSA & Single scattering albedo \\
SZA & Solar zenith angle \\
\hline
\end{tabular}

potential relationship between such "effective" values of $A_{\mathrm{S}}$ and their actual counterparts, additional studies are needed. These studies should include collocated and coincident aircraft (e.g., Coddington et al., 2008; Knobelspiesse et al., 2008) and ground-based (e.g., Michalsky et al., 2003) measurements of surface albedo.

\section{Summary}

We evaluate a new method, called the RR method, using extensive airborne and ground-based datasets collected during the CLASIC and CHAPS, which took place in June 2007 over the DOE ARM SGP site. We perform a detailed case study for a day (12 June 2007) with single-layer shallow cumuli and typical aerosol loading. For this day, independent measurements of AOD are available from aircraft-based HSRL and three ground-based MFRSRs. These HSRLand MFRSR-derived AODs are used for the development of a dataset to evaluate the RR method. Such development includes the temporal and spatial interpolation of the MFRSR-derived AODs and estimation of uncertainties associated with this interpolation. The uncertainties are estimated by interpolating the MFRSR-derived AODs ( $500 \mathrm{~nm}$ ) for the 3-h HSRL fight trajectory and comparing the mean value of MFRSR-derived AOD (along the HSRL track) with that provided by the HSRL $(532 \mathrm{~nm})$. The moderate difference $(\sim 20 \%)$ between the MFRSR and HSRL values suggests that the temporally and spatially interpolated MFRSRderived AODs can give a reasonable AOD estimate for a given time and location, at least for the day of interest.

The RR method utilizes the reflectance ratios at two pairs of wavelengths (660 and $470 \mathrm{~nm})$ and $(870$ and $470 \mathrm{~nm})$ and estimates AOD for clear pixels under partly cloudy conditions (Kassianov and Ovtchinnikov, 2008; Kassianov et al., 2009). The advantage of the RR method over available reflectance-based algorithms is that it reduces substantially the impact of the 3-D radiative effects of clouds on the retrieved AOD, which can be large (up to $140 \%$ ). We apply the RR method to derive spectral values of AOD from the cloudy-sky reflectance ratios provided by the MODIS Airborne Simulator (MAS) with high spatial resolution $(0.05 \mathrm{~km})$. The MFRSR-derived AOD values are interpolated along the MAS fight trajectory and these interpolated values are considered as observational constraint for the evaluation of the RR method. Comparison of the RR- and MFRSRderived AODs reveals that their mean values (along the MAS track) are in a good agreement (within 5\%) for 660-nm wavelength. The RR AODs are greater (by 15-30\%) than the MFRSR ones for 470-nm wavelength. The opposite is true for $870-\mathrm{nm}$ wavelength. The RR-MFRSR differences in spectral dependence could be associated with the sampling and cloud screening issues. The conclusions so far are obtained for a single day with typical single-layer cumuli and typical aerosol loading. More retrievals for different cloud and aerosol types are needed in order to better understand advantages and limitations of the RR method, and hence to improve the aerosol retrievals under partly cloudy conditions.

The results of the case study illustrate the capability of the RR method for retrieving AOD from high-resolution aircraft observations. These observations make it possible to reduce the negative influence of the cloud contamination effect on the AOD retrieval. However, this influence should be more pronounced for coarse-resolution $(0.5-1.0 \mathrm{~km})$ observations provided by satellites, such as the MODIS instrument on the "A-Train" satellite constellation (Stephens et al., 2002). An "A-Train" overpass occurred over the ARCF during the casestudy day (12 June 2007). To understand the influence of spatial resolution on the RR-based AOD retrieval, we plan to apply the RR method to available MODIS observations made at the coarse spatial resolution.

\section{Appendix A}

\section{Interpolation method}

Here we describe an original interpolation technique first reported by Alexandrov et al. (2006). Consider a realization $f(\boldsymbol{x})$ of 2-D Fractional Brownian Motion (FBM) process 
with known statistics of its increments $\Delta f=f(\boldsymbol{x})-f\left(\boldsymbol{x}_{0}\right)$ described by a Gaussian probability distribution

$\varphi(\Delta f)=\frac{1}{\sqrt{2 \pi} s} \exp \left[-\frac{(\Delta f)^{2}}{2 s^{2}}\right]$,

where

$s=\sqrt{E\left[(\Delta f)^{2}\right]}=\sigma|\Delta x|^{H}$

is the standard deviation, expressed in terms of the characteristic dispersion parameter $\sigma$ and the Hurst exponent $H$, which takes values between 0 and 1 . Here $\boldsymbol{x}$ and $\boldsymbol{x}_{0}$ are points on the plane (which can be considered as 2-D vectors in some coordinate system) and $\Delta x$ is the distance between them (the length $\Delta x=\left|x-x_{0}\right|$ of the difference between the corresponding 2-D vectors).

Let $f$ be sampled at a set of $n+1$ points

$\left\{x_{0}, x_{1}, x_{2}, \ldots, x_{n}\right\}$ on the plane and we need to estimate its value $f(\boldsymbol{x})$ at some other point $\boldsymbol{x}$. This is equivalent to estimation of the increment $\Delta f=f(\boldsymbol{x})-f\left(\boldsymbol{x}_{0}\right)$, since $f\left(x_{0}\right)$ is known. We define the sampled increments as

$\Delta f_{i}=f\left(\boldsymbol{x}_{i}\right)-f\left(\boldsymbol{x}_{0}\right), i=1,2, \ldots, n$

and the corresponding distance vectors as $\Delta \boldsymbol{x}_{i}=\boldsymbol{x}_{i}-\boldsymbol{x}_{0}$ with $\Delta x_{i}=\left|\Delta x_{i}\right|$. The choice of a particular "base point" $\boldsymbol{x}_{0}$ among the sampled points does not affect the interpolation results.

The covariance matrix $\boldsymbol{\Sigma}$ of the increments $\Delta f_{i}$ has the elements

$\Sigma_{i j}=E\left[\Delta f_{i} \Delta f_{j}\right]=\sigma^{2}\left(\Delta x_{i} \Delta x_{j}\right)^{H} \rho_{i j}$,

where $\rho_{i j}$ are the elements of the corresponding correlation matrix

$\rho_{i j}=\frac{E\left[\Delta f_{i} \Delta f_{j}\right]}{\sqrt{E\left[\left(\Delta f_{i}\right)^{2}\right] E\left[\left(\Delta f_{j}\right)^{2}\right]}}$,

which in 2-D case can be expressed as

$\rho_{i j}=\frac{1}{2}\left[r_{i j}^{H}+\frac{1}{r_{i j}^{H}}-\left(r_{i j}+\frac{1}{r_{i j}}-2 \cos \alpha_{i j}\right)^{H}\right]$,

where $r_{i j}=\Delta x_{i} / \Delta x_{j}$, and $\alpha_{i j}$ is the angle between the vectors $\boldsymbol{x}_{i}$ and $\boldsymbol{x}_{j}$.

The $(n+1)$ - dimensional random variable $\Delta=$ $\left\{\Delta f, \Delta f_{1}, \Delta f_{2}, \ldots, \Delta f_{\mathrm{n}}\right\}$ obeys the following joint normal distribution:

$\varphi(\Delta)=\frac{\sqrt{|\mathbf{K}|}}{2 \pi^{(n+1) / 2}}$

$\times \exp \left[-\frac{1}{2}\left((\Delta f)^{2} k_{00}+2 \Delta f \sum_{i=1}^{n} k_{0 i} \Delta f_{i}+\sum_{i=1}^{n} \sum_{j=1}^{n} k_{i j} \Delta f_{i} \Delta f_{j}\right)\right]$, where $\mathbf{K}=\boldsymbol{\Sigma}^{-1}, k_{i j}$ are the elements of $\mathbf{K}$ (index "0" corresponds to $\Delta f$ ), and $|\mathbf{K}|=\operatorname{det} \mathbf{K}$. It is not difficult to show that ones $\Delta f_{1}, \Delta f_{2}, \ldots, \Delta f_{\mathrm{n}}$ are fixed, $\Delta f$ obeys normal distribution

$\varphi_{\Delta}(\Delta f)=\frac{1}{\sqrt{2 \pi} S} \exp \left[-\frac{(\Delta f-A)^{2}}{2 S^{2}}\right]$

with the mean

$A=-\frac{1}{k_{00}} \sum_{i=1}^{n} k_{0 i} \Delta f_{i}$

and the dispersion

$S^{2}=\frac{1}{k_{00}}$,

which can be used respectively as the predicted value of $\Delta f$ and the uncertainty of this value.

The Hurst exponent $H$ and the characteristic dispersion $\sigma$ are free parameters of the model and should be defined a priori. Classical Brownian motion corresponds to $H=1 / 2$, while the Kolmogorov's 3-D turbulence to $H=1 / 3$ (Davis et al., 1994). In the study by Alexandrov et al. (2004a) of scaling properties of AOD based on MFRSR measurements from the SGP network values of $H$ ranging from 0.1 to 0.5 were encountered in time series samples. The monthly averaged (September 2000) value of $H$ derived from spatial structure function was 0.32. Based on the results of that paper we have chosen $H=0.3$ and $\sigma=0.002$ for this study. Note that the mean value estimate $A$ is independent from the characteristic dispersion $\sigma^{2}$, thus, interpolation is possible even when $\sigma$ is poorly constrained.

Alexandrov et al. (2006) compared the results of the described interpolation technique with two more standard methods: minimal curvature surface (MCS) and kriging. For that test MFRSR sites were removed (one at a time) from the SGP network, and the AOD values (at $870 \mathrm{~nm}$ ) interpolated from the remaining part of the network to the removed site location were compared with the actual measurements at that site. FBM and MCS results appeared to be similar and generally better than those of kriging. The largest differences occur at the network border, especially if the AOD values from the removed site were not typical for its neighborhood. The mean differences over all sites for MCS, FBM and kriging were respectively $0.0024,0.0026$, and 0.0032 with standard deviations $0.014,0.013$, and 0.025 .

\section{Appendix B}

\section{Development and application of LUTs}

The LUTs are generated using a 1-D version of 3-D Monte Carlo radiative transfer model, which allows one to simulate radiative properties of aerosols and clouds and accounts for 

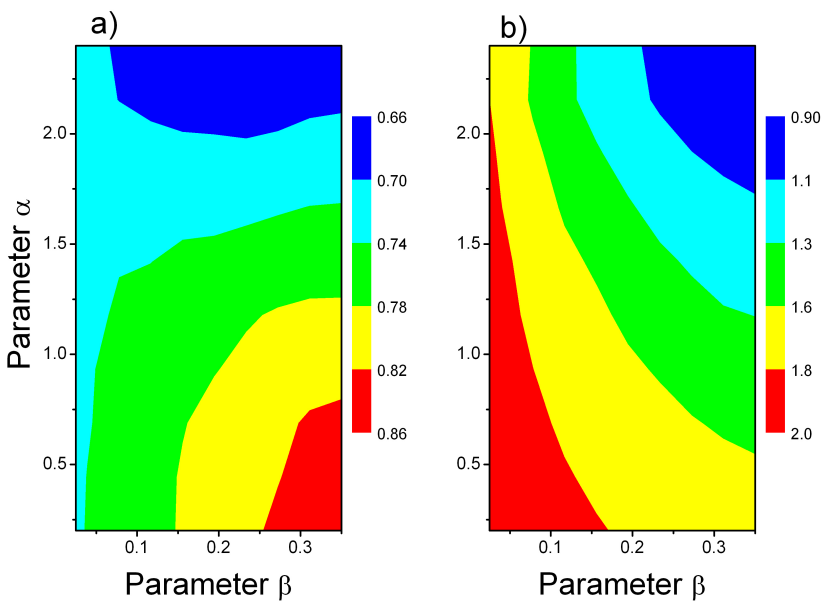

Fig. B1. Example of model reflectance ratios $(\rho)$ generated for $\mathrm{SZA}=40$, and assumed spectral values of the surface albedo $A_{\mathrm{S}}(470)=0.06, A_{\mathrm{S}}(660)=0.07$, and $A_{\mathrm{S}}(870)=0.22$.

the molecular scattering and surface reflection. The model's details and its evaluation are described in Kassianov and Kogan (2002) and Cahalan et al. (2005), respectively. Here we outline the basic steps for the reflectance estimates.

The photon trajectories are simulated using the forward Monte Carlo framework (Marchuk et al., 1980). Within this framework, photons are emitted from initial points $\boldsymbol{r}_{0}^{n}=$ $\left(x_{0}^{n}, y_{0}^{n}, z_{0}\right)$ at the top-of atmosphere $\left(z=z_{0}\right)$ along the sun illumination direction $\boldsymbol{\omega}_{0}=\left(\theta_{0}, \varphi_{0}\right)$, where $n$ is the $n$th photon. The initial weight of each photon is set as $W_{\mathrm{o}}^{n}=1$. The photon path length $l$ is sampled from the probability density of the free path between two successive events (or photonmatter interactions):

$f(l)=\sigma(\boldsymbol{r}(l)) \exp (-\tau(l))$

where $\sigma(\boldsymbol{r}(l))$ is the total extinction coefficient, which represents a sum of the extinction coefficients for individual components (molecular, aerosols, clouds). The optical length of the free path is defined as

$\tau(l)=\int_{0}^{l} \sigma\left(\boldsymbol{r}^{\prime}+s \boldsymbol{\omega}\right) d s$

where $\boldsymbol{r}^{\prime}$ is the initial point of the photon path.

At the scattering event of order $m$, a responsible component (e.g., cloud) is determined and the photon weight is changed accordingly

$W_{\mathrm{m}}^{n}=W_{\mathrm{m}-1}^{n} \varpi(\boldsymbol{r})$

where $\varpi(r)$ is a SSA of the determined responsible component at point $\boldsymbol{r}$ (if the scattering event occurs above surface) or a surface albedo (if the scattering event occurs at surface). If the photon weight is less than a given threshold, the photon trajectory is terminated. An angular redistribution function $\Psi\left(\theta, \varphi ; \theta^{\prime}, \varphi^{\prime}\right)$ is applied for sampling of

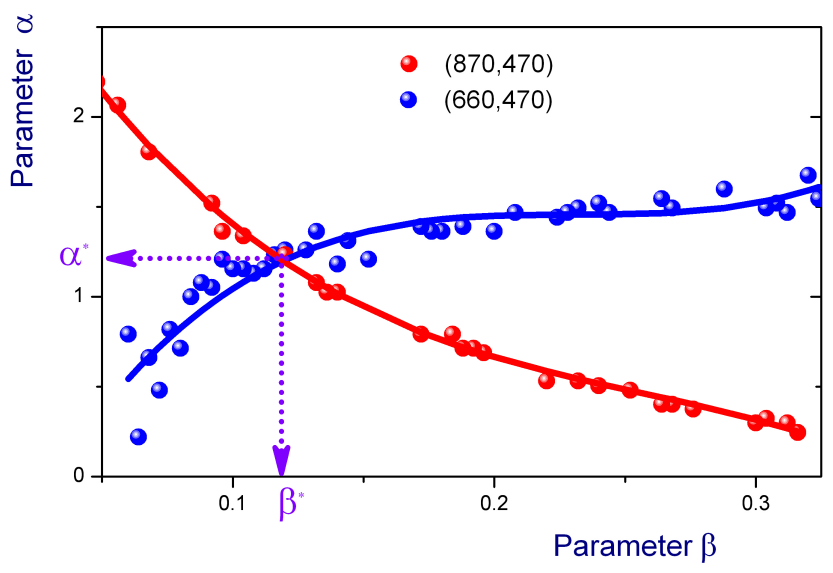

Fig. B2. A family of points where $\rho_{\alpha \beta}=\rho_{\text {obs }}$, the corresponding three-parameter polynomial fits and the obtained solution $\left(\alpha^{*}\right.$ and $\left.\beta^{*}\right)$.

the next scattering direction $\left(\theta^{\prime}, \varphi^{\prime}\right)$. If the $m$-th scattering event occurs above surface, then $\Psi\left(\theta, \varphi ; \theta^{\prime}, \varphi^{\prime}\right)$ is a scattering phase function. If the $m$ th scattering event occurs at surface, then $\Psi\left(\theta, \varphi ; \theta^{\prime}, \varphi^{\prime}\right)$ is a bidirectional reflectance distribution function.

At each collision event, a value of contribution function $h_{\mathrm{m}}^{n}\left(\theta^{*}, \varphi^{*} ; \boldsymbol{r}^{*}\right)$ is calculated

$h_{\mathrm{m}}^{n}\left(\theta^{*}, \varphi^{*} ; \boldsymbol{r}^{*}\right)$

$=W_{\mathrm{m}}^{n} \Psi\left(\theta, \varphi ; \theta^{*}, \varphi^{*}\right) \exp \left(-\tau\left(\boldsymbol{r}, \boldsymbol{r}^{*}\right)\right)$,

where point $\boldsymbol{r}^{*}$ is located within a giving horizontal area $\Delta A$ at the top of atmosphere. The sum of these values over all scattering events and photon trajectories estimates the reflectance $(\Delta A)$. The Monte Carlo algorithm based on contribution function defined by Eq. (B4) is called the "local estimation" method (Marchuk et al., 1980).

The US standard atmosphere (Liou, 1992) and Lambertian surface are assumed in generating the LUTs. The LUTs generating also requires the aerosol phase functions at 470 , 660 and $870 \mathrm{~nm}$, which are calculated using Mie theory and aerosol microphysical properties provided by a Large-Eddy Simulation (Ovtchinnikov and Ghan, 2005) for typical summertime conditions at the ARM SGP site. The aerosol SSA is estimated from aircraft observations (Sect. 2). A twoparameter power law $\left(\tau_{a}(\lambda)=\beta \lambda^{-\alpha}\right)$ is applied for obtaining the AOD at three wavelengths $(470,660$ and $870 \mathrm{~nm})$, where parameter $\alpha$ varies between 0.2 and 2.4 and parameter $\beta$ varies between 0.03 and 0.35 . The aerosol optical properties are used as input for the radiative transfer calculations. The output is the reflectance ratios for two pairs of wavelengths ( 870 and $470 \mathrm{~nm})$ and $(660$ and $470 \mathrm{~nm})$ as function of $\alpha$ and $\beta$ (Fig. B1).

To obtain solution (parameters $\alpha^{*}$ and $\beta^{*}$ ) from the observed reflectance ratios, we apply the generated LUTs as follows. First, we define a family of points $(\tilde{\alpha}, \tilde{\beta})$ where the 
model reflectance ratios $\rho_{\alpha \beta}$ match the observed reflectance ratios $\rho_{\text {obs }}$ (Fig. B2). Then, we define the corresponding polynomial fits (e.g., three-parameter fit). Finally, we obtain the estimates of these two parameters $\alpha^{*}$ and $\beta^{*}$ from the point where these two fits cross each other (Fig. B2).

\section{Appendix C}

\section{Uncertainties of RR-based AOD retrieval}

Uncertainties in the RR-derived AOD could arise from inappropriate assumptions and errors associated with assumed/specified aerosol properties. For example, we apply the aerosol SSA provided by aircraft observations, which has an uncertainty range from $2 \%$ to $7 \%$ (e.g., Sheridan et al., 2001). To estimate the sensitivity of the RR-based AOD retrieval to errors associated with aerosol SSA, we also perform the RR-based AOD retrieval by using another SSA. Specifically, we assume that SSA equals 0.90 at all three wavelengths $(470,660$ and $870 \mathrm{~nm})$. Table $\mathrm{C} 1$ shows that the differences between the mean values of the RR-derived AODs for two cases $(\mathrm{SSA}=0.95$ and $\mathrm{SSA}=0.90)$ are within $5 \%$. The good agreement between these values suggests that the averaged RR-derived AODs are not sensitive to the assumed values of the aerosol SSA. In contrast, the number of points where the RR retrieval provides an AOD is quite sensitive to the assumed SSA (the difference of 18\%). Similar results are obtained for an assumed phase function of atmospheric aerosols (not shown), which could have strong impact on the accuracy of the major satellite-based AOD retrievals (Kokhanovsky et al., 2009).

Also, uncertainties in the RR-derived AOD could arise from inappropriate assumptions about surface albedo. The surface albedo over land is spectrally-dependent and increases generally with wavelength. For the considered wavelengths (470, 660 and $870 \mathrm{~nm}$ ), the largest values of surface albedo occur at $870 \mathrm{~nm}$. To illustrate the sensitivity of the AOD spectral shape to assumed surface albedo at $870 \mathrm{~nm}$ $\left(A_{870}\right)$, we include the domain-averaged values of the retrieved AODs at three wavelengths and the corresponding values of standard deviation (Fig. C1).

The mean values of the retrieved AODs at $660 \mathrm{~nm}$ and $870 \mathrm{~nm}$ do not change substantially with $A_{870}$, while the mean AOD at $470 \mathrm{~nm}$ shows much stronger sensitivity to $A_{870}$. As a result, the Angstrom exponent (470-870 nm) of the retrieved AOD depends noticeably on the assumed surface albedo $A_{870}$ : it changes from 1.20 at $A_{870}=0.20$ to 1.54 at $A_{870}=0.32$. Note that the estimation of Angstrom exponent from the reflected solar radiation is much less accurate than the estimation of AOD at a given wavelength (e.g., Mischchenko et al., 2010). The standard deviation values, which provide a measure of variability of the RR-retrieved AODs, are not very sensitive to the assumed surface albedo (Fig. C1). We emphasize that different number of pixels with
Table C1. The number of points with the RR-derived AODs (leg 10) and the corresponding mean values of AOD at three wavelengths (470, 660 and $870 \mathrm{~nm})$ obtained for two cases with different assumptions about aerosol SSA.

\begin{tabular}{ccccc}
\hline $\begin{array}{c}\text { Assumed } \\
\text { SSA }\end{array}$ & $\begin{array}{c}\text { Number of } \\
\text { points }\end{array}$ & AOD (470) & AOD (660) & AOD (870) \\
\hline 0.95 & 701 & 0.306 & 0.192 & 0.135 \\
0.90 & 577 & 0.303 & 0.186 & 0.128 \\
& $17.7 \%$ & $1.0 \%$ & $3.3 \%$ & $4.9 \%$ \\
\hline
\end{tabular}
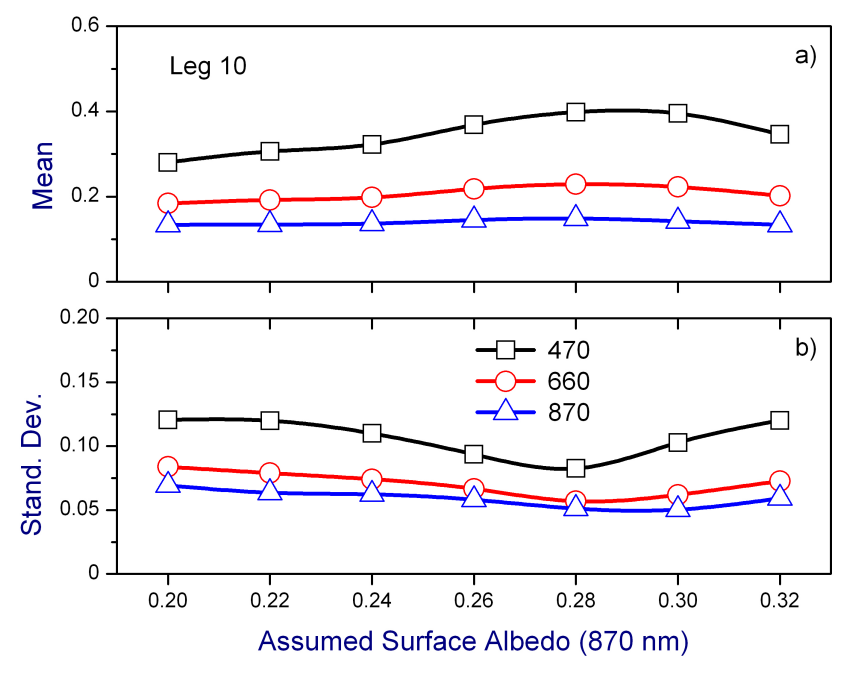

Fig. C1. Mean values of the RR-retrieved AOD (leg 10) at three wavelengths $(470,660$ and $870 \mathrm{~nm})$ (a) and the corresponding values of standard deviation obtained for seven cases with different assumptions about surface albedo at $870 \mathrm{~nm}$.

retrieved AOD are used for obtaining the considered basic statistics and this number depends strongly on the assumed surface albedo (Fig. 6).

The RR method is based on the combined radiative parameters (reflectance ratios), which show weak sensitivity to the 3-D radiative effects of clouds (Kassianov and Ovtchinnikov, 2008). However, its current version includes only two constraints, and thus only two aerosol parameters can be retrieved. Moreover, several aerosol properties, including SSA and phase function, are assumed. Finally, information about surface albedo is required. These assumptions can be relaxed if supplementary constraints are employed. These constraints can be obtained from combined passive and active observations with multi-spectral, multi-angular and/or polarimetric capabilities (e.g., Litvinov et al., 2010). Typically, combined observations are performed during intensive field campaigns, such as the Aerosol Lidar Validation experiment (e.g., Waquet et al., 2009) or the MILAGRO (Megacity Initiative: Local And Global Research Observations) (e.g., Molina et al., 2010). 
The current version of the RR method can estimate quite accurately the averaged values of the AOD for cases with moderate-to-large aerosol loading (AOD >0.1). However, it performs poorly in the close vicinity of clouds $(\sim 0.1-$ $0.3 \mathrm{~km})$. The corresponding errors of the RR-derived AOD depend on the cloud fraction and COD and can exceed $100 \%$ (Kassianov et al., 2009). Since the largest changes of aerosol properties occur near clouds (e.g., Su et al., 2008; Chiu et al., 2008), the RR method is not well suited for describing them.

Acknowledgements. This work was supported by the National Aeronautics and Space Administration (NASA) through the Radiation Sciences Program and the Office of Biological and Environmental Research (OBER) of the US Department of Energy (DOE) as part of the Atmospheric Radiation Measurement (ARM) Program and Atmospheric Science Program (ASP). The Pacific Northwest National Laboratory (PNNL) is operated by Battelle for the DOE under contract DE-AC06-76RLO 1830. This research was performed in part using the Molecular Science Computing Facility (MSCF) in the Environmental Molecular Sciences Laboratory (EMSL), a national scientific user facility sponsored by the US DOE, OBER and located at PNNL. We are grateful to James Barnard and Alexander Kokhanovsky and anonymous reviewers for thoughtful comments.

Edited by: A. A. Kokhanovsky

\section{References}

Albrecht, B.: Aerosols, cloud microphysics, and fractional cloudiness, Science, 245, 1227-1230, doi:10.1126/science.245.4923.1227, 1989.

Alexandrov, M. D., Marshak, A., Cairns, B., Lacis, A. A., and Carlson, B. E.: Scaling properties of aerosol optical thickness retrieved from ground-based measurements, J. Atmos. Sci., 61, 1024-1039, 2004a.

Alexandrov, M., Marshak, A., Cairns, B., Lacis, A. A., and Carlson, B. E.: Automated cloud screening algorithm for MFRSR data, Geophys. Res. Lett., 31, L04118, doi:10.1029/2003GL019105, 2004b.

Alexandrov, M., Lacis, A., Carlson, B., and Cairns, B.: New Developments in Multi-Filter Rotating Shadowband Radiometer Data Analysis, Paper presented at the Sixteenth Atmospheric Radiation (ARM) Science Team Meeting, US Department of Energy, Richland, WA, 2006.

Andrews, E., Sheridan, P. J., Ogren, J. A., and Ferrare, R.: In situ aerosol profiles over the Southern Great Plains cloud and radiation test bed site: 1. Aerosol optical properties, J. Geophys. Res., 109, D06208, doi:10.1029/2003JD004025, 2004.

Baum, B. A., Kratz, D. P., Yang, P., Ou, S., Hu, Y., Soulen, P. F., and Tsay, S.-C.: Remote sensing of cloud properties using MODIS Airborne Simulator imagery during SUCCESS, I. Data and models, J. Geophys. Res., 105, 11767-11780, 2000.

Berg, L. K., Berkowitz, C. M., Hubbe, J. M., Ogren, J. A., Hostetler, C. A., et al.: Overview of the Cumulus Humilis Aerosol Processing Study, B. Am. Meteorol. Soc., 90, 1653-1667, 2009.
Cahalan, R. F., Oreopoulos, L., Wen, G., Marshak, A., Tsay, S.-C., and DeFelice, T.: Cloud characterization and clear sky correction from Landsat 7, Remote Sens. Environ., 78, 83-98, 2001.

Cahalan, R. F., Oreopoulos, L., Marshak, A., Evans, K. F., Davis, A. B., et al.: The International Intercomparison of 3-D Radiation Codes (I3RC): Bringing together the most advanced radiative transfer tools for cloudy atmospheres, B. Am. Meteorol. Soc., 86, 1275-1293, 2005.

Chiu, J. C., Marshak, A., Knyazikhin, Y., Pilewski, P., and Wiscombe, W. J.: Physical interpretation of the spectral radiative signature in the transition zone between cloud-free and cloudy regions, Atmos. Chem. Phys., 9, 1419-1430, doi:10.5194/acp-91419-2009, 2009.

Coddington, O., Schmidt, K. S., Pilewskie, P., Gore, W. J., Bergstrom, R. W., Román, M., Redemann, J., Russell, P. B., Liu, J., and Schaaf, C. C.: Aircraft measurements of spectral surface albedo and its consistency with ground-based and space-borne observations, J. Geophys. Res., 113, D17209, doi:10.1029/2008JD010089, 2008.

Davis, A., Marshak, A., Wiscombe, W., and Cahalan, R.: Multifractal characterizations of nonstationarity and intermittency in geophysical fields: Observed, retrieved, or simulated, J. Geophys.Res., 99, 8055-8072, 1994.

Hair, J. W., Hostetler, C. A., Cook, A. L., Harper, D. B., Ferrare, R. A., Mack, T. L., Welch, W., Izquierdo, L. R., and Hovis, F. E.: Airborne High Spectral Resolution Lidar for profiling aerosol optical properties, Appl. Optics, 47, 6734-6752, 2008.

Harrison, L. and Michalsky, J.: Objective algorithms for the retrieval of optical depths from ground-based measurements, Appl. Optics, 33, 5126-5132, 1994.

Kassianov, E., Ovchinnikov, M., Berg, L. K., McFarlane, S. A., and Flynn, C.: Retrieval of aerosol optical depth in vicinity of broken clouds from reflectance ratios: Sensitivity study, J. Quant. Spectrosc. Ra., 110, 1677-1689, 2009.

Kassianov, E. and Kogan, Y. L.: Spectral Dependence of Radiative Horizontal Transport in Stratocumulus Clouds and Its Effect on Near-IR Absorption, J. Geophys. Res., 107(D23), 4712, doi:10.1029/2002JD002103, 2002.

Kassianov, E. I., Barnard, J. C., and Ackerman, T. P.: Retrieval of Aerosol Microphysical Properties Using Surface MultiFilter Rotating Shadowband Radiometer (MFRSR) Data: Modeling and Observations, J. Geophys. Res., 110(D9), D09201, doi:10.1029/2004JD005337, 2005.

Kassianov, E. I., Flynn, C. J., Ackerman, T. P., and Barnard, J. C.: Aerosol single-scattering albedo and asymmetry parameter from MFRSR observations during the ARM Aerosol IOP 2003, Atmos. Chem. Phys., 7, 3341-3351, doi:10.5194/acp-7-3341-2007, 2007.

Kassianov, E. and Ovtchinnikov, M.: On reflectance ratios and aerosol optical depth retrieval in the presence of cumulus clouds, Geophys. Res. Lett., 35, L06807, doi:10.1029/2008GL033231, 2008.

Katsev, I. L., Prikhach, A. S., Zege, E. P., Grudo, J. O., and Kokhanovsky, A. A.: Speeding up the AOT retrieval procedure using RTT analytical solutions: FAR code, Atmos. Meas. Tech. Discuss., 3, 1645-1705, doi:10.5194/amtd-3-1645-2010, 2010.

King, M. D., Menzel, W. P., Grant, P. S., Myers, J. S., Arnold, G. T., et al.: Airborne scanning spectrometefror remote sensing of cloud, aerosol, water vapor, and surface properties, J. Atmos. 
Ocean. Tech., 13, 777-794, 1996.

King, M. D., Platnick, S., Wind, G., Arnold, G. T., and Dominguez, R. T.: Remote sensing of radiative and microphysical properties of clouds during $\mathrm{TC}^{4}$ : Results from MAS, MASTER, MODIS, and MISR, J. Geophys. Res., 115, D00J07, doi:10.1029/2009JD013277, 2010.

Knobelspiesse, K. D., Cairns, B., Schmid, B., Román, M. O., and Schaaf, C. B.: Surface BRDF estimation from an aircraft compared to MODIS and ground estimates at the Southern Great Plains site, J. Geophys. Res., 113, D20105, doi:10.1029/2008JD010062, 2008.

Kobayashi, T., Masuda, K., Sasaki, M., and Mueller, J.: Monte Carlo simulations of enhanced visible radiance in clear-air satellite fields of view near clouds, J. Geophys. Res., 105, 2656926576, 2000.

Kokhanovsky, A. A. and de Leeuw, G.: Satellite Aerosol Remote Sensing over Land, Praxis Publishing, UK, 388 pp., 2009.

Kokhanovsky, A. A., Deuzé, J. L., Diner, D. J., Dubovik, O., Ducos, F., Emde, C., Garay, M. J., Grainger, R. G., Heckel, A., Herman, M., Katsev, I. L., Keller, J., Levy, R., North, P. R. J., Prikhach, A. S., Rozanov, V. V., Sayer, A. M., Ota, Y., Tanré, D., Thomas, G. E., and Zege, E. P.: The inter-comparison of major satellite aerosol retrieval algorithms using simulated intensity and polarization characteristics of reflected light, Atmos. Meas. Tech., 3, 909-932, doi:10.5194/amt-3-909-2010, 2010.

Liou, K. N.: Radiation and Cloud Processes in the Atmosphere, Oxford Univ. Press, New York, 1992.

Litvinov, P., Hasekamp, O., Cairns, B., and Mishchenko, M.: Reflection models for soil and vegetation surfaces from multipleviewing angle photopolarimetric measurements. J. Quant. Spectrosc. Ra., 111, 529-539, 2010.

Loeb, N. G. and Schuster, G. L.: An observational study of the relationship between cloud, aerosol and meteorology in broken low-level cloud conditions, J. Geophys. Res., 113, D14214, doi:10.1029/2007JD009763, 2008.

Luo, Y., Trishchenko, A., Latifovic, R., and Li, Z.: Surface bidirectional reflectance and albedo properties derived using a land cover-based approach with Moderate Resolution Imaging Spectroradiometer observations, J. Geophys. Res., 110, D01106, doi:10.1029/2004JD004741, 2005.

Marchuk, G., Mikhailov, G., Nazaraliev, M., Darbinjan, R., Kargin, B., and Elepov, B.: The Monte Carlo Methods in Atmospheric Optics, Springer-Verlag, 208 pp., 1980.

Marshak, A., Wen, G., Coakley, J., Remer, L., Loeb, N., and Cahalan, R.: A simple model for the cloud adjacency effect and the apparent bluing of aerosols near clouds, J. Geophys. Res., 113, D14S17, doi:10.1029/2007JD009196, 2008.

Matheson, M. A., Coakley, J. A., and Tahnk, W. R.: Aerosol and cloud property relationships for summertime stratiform clouds in the northeastern Atlantic from Advanced Very High Resolution Radiometer observations, J. Geophys. Res., 110, D24204, doi:10.1029/2005JD006165, 2005.

Michalsky, J., Min, Q., Barnard, J., Marchand, R., and Pilewskie, P.: Simultaneous spectral albedo measurements near the Atmospheric Radiation Measurement Southern Great Plains (ARM SGP) central facility, J. Geophys. Res., 108, 4254, doi:10.1029/2002JD002906, 2003.

Michalsky, J. J., Anderson, G. P., Barnard, J., Delamere, J., Gueymard, C., Kato, S., Kiedron, P., McComiskey, A., and Ricchiazzi,
P.: Shortwave radiative closure studies for clear skies during the Atmospheric Radiation Measurement 2003 Aerosol Intensive Observation Period, J. Geophys. Res., 111, D14S90, doi:10.1029/2005JD006341, 2006.

Miller, M. A., Avissar, R., Berg, L., Edgerton, S., Fischer, M., et al.: SGP Cloud and Land Surface Interaction Campaigns (CLASIC), US Department of Energy, DOE/SC-ARM-0703, 14 pp., 2007.

Mishchenko, M. I., Geogdzhayev, I. V., Liu, L., Lacis, A. A., Cairns, B., and Travis, L. D.: Toward unified satellite climatology of aerosol properties: What do fully compatible MODIS and MISR aerosol pixels tell us?, J. Quant. Spectrosc. Ra., 110, 402408, 2009.

Mishchenko, M. I., Liu, L., Geogdzhayev, I. V., Travis, L. D., Cairns, B., and Lacis, A. A.: Toward unified satellite climatology of aerosol properties. 3. MODIS versus MISR versus AERONET, J. Quant. Spectrosc. Ra., 111, 540-552, 2010.

Molina, L. T., Madronich, S., Gaffney, J. S., Apel, E., de Foy, B., Fast, J., Ferrare, R., Herndon, S., Jimenez, J. L., Lamb, B., Osornio-Vargas, A. R., Russell, P., Schauer, J. J., Stevens, P. S., Volkamer, R., and Zavala, M.: An overview of the MILAGRO 2006 Campaign: Mexico City emissions and their transport and transformation, Atmos. Chem. Phys., 10, 8697-8760, doi:10.5194/acp-10-8697-2010, 2010.

Nikolaeva, O. V., Bass, L. P., Germogenova, T. A., Kokhanovisky, A. A., Kuznetsov, V. S., and Mayer, B.: The influence of neighboring clouds on the clear sky reflectance with the 3-D transport code RADUGA, J. Quant. Spectrosc. Ra., 94, 405-424, 2005.

Ovtchinnikov, M. and Ghan, S. J.: Parallel simulations of aerosol influence on clouds using a cloud-resolving model and a single column model, J. Geophys. Res., 110, D15S10, doi:10.1029/2004JD005088, 2005.

Redemann, J., Zhang, Q., Russell, P. B., Livingston, J. M., and Remer, L. A.: Case studies of aerosol remote sensing in the vicinity of clouds, J. Geophys. Res., 114, D06209, doi:10.1029/2008JD010774, 2009.

Remer, L. A., Kaufman, Y. J., Tanre, D., Mattoo, S., Chu, D. A., et al.: The MODIS aerosol algorithm, products and validation, J. Atmos. Sci., 62, 947-973, 2005.

Rogers, R. R., Hair, J. W., Hostetler, C. A., Ferrare, R. A., Obland, M. D., Cook, A. L., Harper, D. B., Burton, S. P., Shinozuka, Y., McNaughton, C. S., Clarke, A. D., Redemann, J., Russell, P. B., Livingston, J. M., and Kleinman, L. I.: NASA LaRC airborne high spectral resolution lidar aerosol measurements during MILAGRO: observations and validation, Atmos. Chem. Phys., 9, 4811-4826, doi:10.5194/acp-9-4811-2009, 2009.

Sheridan, P. J., Delene, D. J., and Ogren, J. A.: Four years of continuous surface aerosol measurments from the Department of Energy's Atmospheric Radiation Measurement Program Southern Great Plains Cloud and Radiation Testbed site, J. Geophy. Res., 106, 20735-20747, 2001.

Small, J. D., Chuang, P. Y., Feingold, G., and Jiang, H.: Can aerosol decrease cloud lifetime?, Geophys. Res. Lett., 36, L16806, doi:10.1029/2009GL038888, 2009.

Stephens, G. L., Vane, D. G., Boain, R. J., Mace, G. G., Sassen, K., et al.: The CLOUDSAT mission and the A-train, B. Am. Meteorol. Soc., 83, 1771-1790, 2002.

Stevens, B. and Feingold, G.: Untangling aerosol effects on clouds and precipitation in a buffered system, Nature, 461, 607-613, doi:10.1038/nature08281, 2009. 
Su, W., Schuster, G. L., Loeb, N. G., Rogers, R. R., Ferrare, R. A., Hostetler, C. A., Hair, J. W., and Obland, M. D.: Aerosol and cloud interaction observed from high spectral resolution lidar data, J. Geophys. Res., 113, D24202, doi:10.1029/2008JD010588, 2008.

Tackett, J. L. and Di Girolamo, L.: Enhanced aerosol backscatter adjacent to tropical trade wind clouds revealed by satellite-based lidar, Geophys. Res. Lett., 36, L14804, doi:10.1029/2009GL039264, 2009.

Twohy, C. H., Coakley Jr., J. A., and Tahnk, W. R.: Effect of changes in relative humidity on aerosol scattering near clouds, J. Geophys. Res., 114, D05205, doi:10.1029/2008JD010991, 2009.

Twomey, S.: The influence of pollution on the shortwave albedo of clouds, J. Atmos. Sci. 34, 1149-1152, 1977.

Várnai, T. and Marshak, A.: MODIS observations of enhanced clear sky reflectance near clouds, Geophys. Res. Lett., 36, L06807, doi:10.1029/2008GL037089, 2009.

von Hoyningen-Huene, W., Freitag, M., and Burrows, J. B.: Retrieval of aerosol optical thickness over land surfaces from top-of-atmosphere radiance, J. Geophys. Res., 108, 4260, doi:10.1029/2001JD002018, 2003.

Waquet, F., Cairns, B., Knobelspiesse, K., Chowdhary, J., Travis, L. D., Schmid, B., and Mishchenko, M. I.: Polarimetric remote sensing of aerosols over land, J. Geophys. Res., 114, D01206, doi:10.1029/2008JD010619, 2009.
Warner, J.: A reduction in rainfall associated with smoke from sugarcane fires - And inadvertent weather modification?, J. Appl. Meteorol., 7, 247-251, 1968.

Wen, G., Marshak, A., and Cahalan, R.: Impact of 3-D clouds on clear sky reflectance and aerosol retrieval in a biomass burning region of Brazil, Geosci. Remote Sens. Lett., 3, 169-172, doi:10.1109/LGRS.2005.861386, 2006.

Wen, G., Marshak, A., Cahalan, R., Remer, L., and Kleidman, R.: 3-D aerosol-cloud radiative interaction observed in collocated MODIS and ASTER images of cumulus cloud fields, J. Geophys. Res., 112, D13204, doi:10.1029/2006JD008267, 2007.

Wen, G., Marshak, A., and Cahalan, R. F.: Importance of molecular Rayleigh scattering in the enhancement of clear sky reflectance in the vicinity of boundary layer cumulus clouds, J. Geophys. Res., 113, D24207, doi:10.1029/2008JD010592, 2008.

Yang, F., Mitchell, K., Hou, Y. T., Dai, Y., Zeng, X., Wang, Z., and Liang, X. Z.: Dependence of Land Surface Albedo on Solar Zenith Angle: Observations and Model Parameterization, J. Appl. Meteorol. Clim., 47, 2963-2982, 2008.

Yang, Y. and Di Girolamo, L.: Impacts of 3-D radiative effects on satellite cloud detection and their consequences on cloud fraction and aerosol optical depth retrievals, J. Geophys. Res., 113, D04213, doi:10.1029/2007JD009095, 2008.

Zhao, G., Di Girolamo, L., Dey, S., Jones, A. L., and Bull, M.: Examination of direct cumulus contamination on MISR-retrieved aerosol optical depth and angstrom coefficient over ocean, Geophys. Res. Lett., 36, L13811, doi:10.1029/2009GL038549, 2009. 